\title{
Evaluation of SuperLig 639 Ion Exchange Resin for the Removal of Rhenium from Hanford Envelope A Simulant
}

by

W. D. King

Westinghouse Savannah River Company

Savannah River Site

Aiken, South Carolina 29808

D. J. McCabe

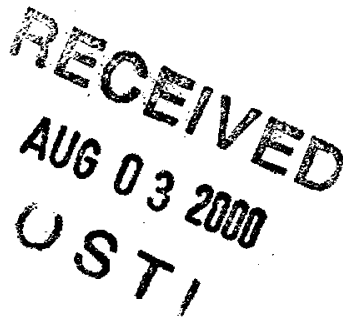

N. M. Hassan

R. Hayden (Contact)

This paper was prepared in connection with work done under the above contract number with the U.S.

Department of Energy. By acceptance of this paper, the publisher and/or recipient acknowledges the U. S.

Government's right to retain a nonexclusive, royalty-free license in and to any copyright covering this paper, along with the right to reproduce and to authorize others to reproduce all or part of the copyrighted paper. 


\section{DISCLAIMER}

This report was prepared as an account of work sponsored by an agency of the United States Government. Neither the United States Government nor any agency thereof, nor any of their employees, makes any warranty, express or implied, or assumes any legal liability or responsibility for the accuracy, completeness, or usefulness of any information, apparatus, product or process disclosed, or represents that its use would not infringe privately owned rights. Reference herein to any specific commercial product, process or service by trade name, trademark, manufacturer, or otherwise does not necessarily constitute or imply its endorsement, recommendation, or favoring by the United States Government or any agency thereof. The views and opinions of authors expressed herein do not necessarily state or reflect those of the United States Government or any agency thereof.

This report has been reproduced directly from the best available copy.

Available for sale to the public, in paper, from: U.S. Department of Commerce, National Technical Information Service, 5285 Port Royal Road, Springfield, VA 22161, phone: (800) 553-6847, fax: (703) 605-6900 email: orders@ntis.fedworld.gov online ordering: http://www.ntis.gov/ordering.htm

Available electronically at http://www.doe.gov/bridge A vailable for a processing fee to U.S. Department of Energy and its contractors, in paper, from: U.S. Department of Energy, Office of Scientific and Technical Information, P.O. Box 62, Oak Ridge, TN 37831-0062, phone: (865)576-8401, fax: (865)576-5728 email: reportsladonis.osti.gov 


\section{DISCLAIMER}

Portions of this document may be illegible in electronic image products. Images are produced from the best available original document. 
BNF-003- 98-0140

Revision 0

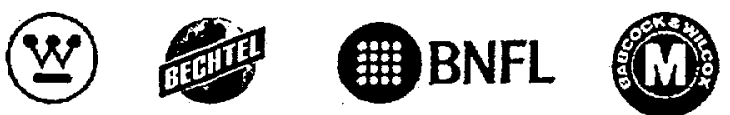

\section{Evaluation of SuperLig ${ }^{\circledR 3} 63$ Ion Exchange Resin for the Removal of Rhenium from Hanford Envelope A Simulant}

April 13, 2000

W. D. King, 773-42A

D. J. McCabe, 773-42A

N. M. Hassan, 773-A Amblass 5

\section{DISCLAIMER NOTICE}

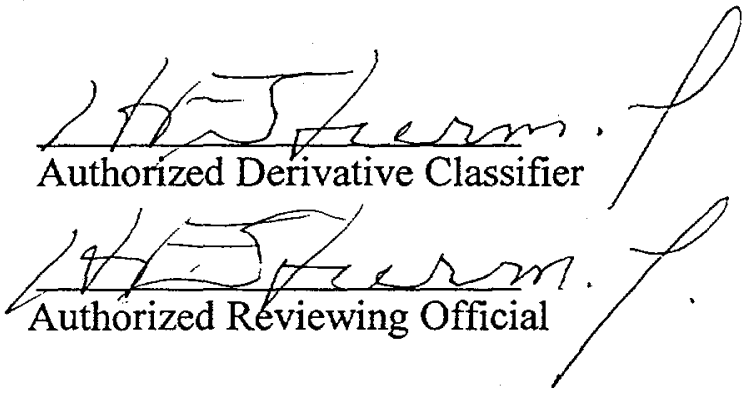

This report was prepared by Westinghouse Savannah River Company, Inc. (WSRC) on behalf of the U.S. Department of Energy (DOE), as an account of work sponsored by BNFL, Inc. Neither WSRC, DOE, the U.S. Government, or any person acting on their behalf makes any warranty, express or implied, or assumes any legal liability or responsibility for the accuracy, completeness, or usefulness of any information, apparatus, product, or process disclosed, or represents that its use would not infringe privately owned rights. Reference herein to any specific commercial product, process, or service by trade name, trademark, manufacturer, or otherwise, does not necessarily constitute or imply its endorsement, recommendation, or favoring by WSRC, DOE, or the U.S. Government. The views and opinions of authors expressed herein do not necessarily state or reflect those of WSRC, DOE, or the U.S. Government.

Savannah River Technology Center

Westinghouse Savannah River Company

Aiken, SC 29808 
Table of Contents

List of Tables iii

List of Figures $\quad$ - iv

SUMMARY v v v

1.0 INTRODUCTION 2

2.0 EXPERIMENTAL 4

2.1. Materials 4

2.2 Equipment and Procedures 5

2.2.1 Batch Contact Experiments $\quad 5$

2.2.2 Column Experiments $\quad 6$

$\begin{array}{llr}3.0 & \text { RESULTS AND DISCUSSION } & 8\end{array}$

3.1 Batch Contact Experiments $\quad 8$

3.2 Column Experiments 11

$\begin{array}{lll}4.0 & \text { CONCLUSIONS } & 18\end{array}$

$\begin{array}{lll}\text { 5.0 DESIGN CHECK } & 18\end{array}$

$\begin{array}{lll}6.0 & \text { APPROVALS } & 18\end{array}$

$\begin{array}{ll}\text { 7.0 REFERENCES } & 19\end{array}$

$\begin{array}{ll}8.0 & \text { APPENDIX } \\ & 20\end{array}$

8.1 Attachment 1. SuperLig ${ }^{\circledR} 639$ Batch Contact Data 20

8.2 Attachment 2. SuperLig ${ }^{\circledR} 639$ Column Data 23

8.3 Attachment 3. Flow Rate Analysis for SuperLig 639

Column Feed, Wash and Elution Cycles 


\section{LIST OF TABLES}

Table 1. Physical characteristics of "as received" SuperLig ${ }^{\circledR} 639$ resins $\quad 4$

Table 2. 241-AN-105 (Env. A) Simulant Composition 5

Table 3. Rhenium Distribution Coefficients $\left(\mathrm{K}_{\mathrm{d}}\right)$ Measured for SuperLig ${ }^{\circledR} 639$

$\begin{array}{ll}\text { Resin Batches } & 10\end{array}$

Table 4. SuperLig ${ }^{\circledR} 639$ Column Re Breakthrough Summary 11 


\section{LIST OF FIGURES}

Figure 1. SuperLig ${ }^{\circledR}$ Ion Exchange Resin Testing Summary

Figure 2. Ion Exchange Column Design

Figure 3. SuperLig $^{\circledR} 639$ Batch Comparison - Final [Re] versus $K_{d}$

Figure 4. SuperLig ${ }^{\circledR} 639$ Batch \#980624001DC Rhenium Breakthrough Profiles

Figure 5. SuperLig ${ }^{\circledR} 639$ Batch \#980624001DC Elution Profiles

Figure 6. SuperLig ${ }^{\circledR} 639$ Batch \#980624001DC Elution Profiles - Semi-Log Plot

Figure 7. SuperLig ${ }^{\circledR} 639$ Batch \#980624001DC Rhenium Breakthrough Profiles Column L/D Comparison

Figure 8. SuperLig ${ }^{\circledR} 639$ Batch \#980624001DC Water Elution Profiles -

Column L/D Comparison

Figure 9. SuperLig ${ }^{\circledR} 639$ Rhenium Breakthrough Profiles - Batch Comparison

Figure 10. SuperLig ${ }^{\circledR} 639$ Water Elution Profile-Mixture of Batches 


\section{SUMMARY}

Tests have been completed that provide basic information on the removal of pertechnetate ion from Hanford tank waste. This work was conducted in support of the Hanford River Protection Project for BNFL, Inc. SuperLig ${ }^{\circledR} 639$ ion exchange resin has been evaluated for the removal of perrhenate ion from Hanford Envelope A simulant. Perrhenate ion was used as a non-radioactive substitute for pertechnetate ion which is the major form of technetium found in actual Envelope A waste samples. Batch contact and column experiments have been performed using SuperLig ${ }^{\circledR} 639$ resin and $5 \mathrm{M}\left[\mathrm{Na}^{+}\right]$ simulant. The tests were highly successful in demonstrating the effectiveness of this method for removing pertechnetate from Hanford tank waste. These results will provide a critical link between small-scale radioactive tests and pilot-scale simulant tests. Results of testing at each scale will serve as input for the development of an ion exchange model which will be used to predict resin performance in the plant operation. No significant problems were encountered which would prevent use of this resin as planned. Further testing is needed to evaluate methods for reducing the volume and duration of elution.

Although all resin batches satisfy the current BNFL design criteria, significant variability was observed in the capacities of the three batches of SuperLig ${ }^{\circledR} 639$ resin received. Distribution coefficients $\left(\mathrm{K}_{d}\right)$ measured in batch contact tests for the "as-received" resins varied by a factor of 2.5 (measured $\mathrm{K}_{d}$ range at $7 \mathrm{mg} / \mathrm{L}$ initial [Re]: $200-500 \mathrm{~mL} / \mathrm{g}$ ). Equilibrium adsorption isotherms were determined for two resin batches by varying the initial rhenium concentration. The rhenium breakthrough in column experiments with different resin batches was consistent with the lambda values predicted from the $\mathrm{K}_{\mathrm{d}}$ data. (Note: All solutions were passed through the ion exchange columns in the downflow direction.) The $50 \% \operatorname{Re}$ breakthrough point ranged from 90 to 150 resin bed volumes (BV) in tests performed with a $2.7 \mathrm{~cm}$ ID column and a superficial velocity near 0.5 $\mathrm{cm} / \mathrm{min}$ ([Re] in feed: $13-16 \mathrm{mg} / \mathrm{L}$ ) depending on the batch of resin tested. For resin batch \#980624001DC experiments were performed in a $2.7 \mathrm{~cm}$ ID column at three flow rates chosen to span the range of superficial velocities that are planned for facility operation. An additional experiment was conducted using the same sample of resin in a $4.0 \mathrm{~cm}$ ID column in order to explore the effects of column geometry on resin performance. At a superficial velocity near $0.5 \mathrm{~cm} / \mathrm{min}$, a $39 \%$ decrease in the volume of solution processed to reach $50 \%$ rhenium breakthrough was observed for the larger diameter column. This result was expected since the residence time and path length (resin bed height) were shorter in the larger diameter column. In the $2.7 \mathrm{~cm}$ ID column, floating of the SuperLig ${ }^{\circledR} 639$ resin bed during the feed cycle was not significant ( $\leq 5 \%$ floating in $5 \mathrm{M}\left[\mathrm{Na}^{+}\right]$simulant for all resin batches tested). There were no observations of cracking or swelling of the resin bed and no color or fines were observed in the effluent. With the $4.0 \mathrm{~cm}$ ID column (batch \#980624001DC), as much as $25 \%$ of the resin bed floated (probably due to less extensive bridging of the resin beads in the larger diameter column) before the bed was retained with quartz wool and glass beads. Another important objective of this work was to determine the appropriate fluid to use for column elution. Columns were eluted with both $0.5 \mathrm{M}$ nitric acid and deionized water.

Deionized water was found to elute the rhenium more quickly than acid, although 16 bed volumes of effluent were required to reach the acceptance criteria $\left(1 \%\right.$ of $\left.\mathrm{C}_{\mathrm{o}}\right)$. 


\subsection{INTRODUCTION}

Hanford RadioactiveWaste materials have been categorized into four envelopes labeled A through $D$ as specified in the Tank Waste Remediation Contract between BNFL and DOE. ${ }^{1}$ Envelopes A, B and C contain only solubilized species and are specified as LowActivity Waste (LAW). Each envelope is defined based on compositional maximums of chemical and radioactive constituents. Envelopes $A$ and $B$ contain low concentrations of organic species and the primary form of technetium is pertechnetate $\left(\mathrm{TcO}_{4}\right)$. Envelope $\mathrm{C}$ contains higher levels of organic species and technetium which is primarily in the nonpertechnetate form (presumably complexed $\mathrm{TcO}_{2}$ ). Envelope $\mathrm{D}$ is sludge which has been separated from the supernate and is referred to as High Activity Waste. The current plant design utilizes SuperLig ${ }^{\circledR}$ ion exchange resins to remove cesium and technetium (the primary radioactive constituents) from the Hanford LAW. The process is designed to produce a decontaminated waste stream and a concentrated eluate waste stream for vitrification into low and high activity glasses, respectively.

The conceptualized process for pretreatment of Hanford LAW utilizes SuperLig ${ }^{\circledR} 639$ ion exchange resin (a proprietary material) for the removal of Tc-99 (pertechnetate form only). SuperLig ${ }^{\circledR} 639$ is an elutable, organic resin prepared by attaching a highlyselective ion exchange material to preformed polystyrene beads. The resin removes a salt pair (e.g. $\mathrm{NaTcO}_{4}$ and $\mathrm{NaNO}_{3}$ ) from acidic or basic solutions. Nitrate anion concentration in the solid is inversely related to the adsorption of pertechnetate from the contacting solution. Other anions typically present in Hanford waste solutions (e.g. $\mathrm{Cl}^{-}$, $\mathrm{F}^{-}, \mathrm{CO}_{3}{ }^{2-}, \mathrm{NO}_{2}{ }^{-}, \mathrm{OH}^{-}, \mathrm{SO}_{4}{ }^{2-}$ ) do not significantly affect the adsorption of pertechnetate by SuperLig ${ }^{\circledR} 639$ resin.

As shown in Figure 1, the current phase of the Hanford River Protection Project includes ion exchange testing of actual samples or nonradioactive simulants of each LAW envelope (A, B and C) at the Savannah River Technology Center (SRTC) and the Pacific Northwest National Laboratory. This report describes the intermediate-scale tests performed on simulated Envelope A solutions at SRTC. The principal objective of these intermediate-scale tests (resin bed volume: $\sim 50 \mathrm{~mL}$ ) was to provide data for computer modeling, allowing comparison of small-scale radioactive tests (resin bed volume: $\sim 6$ $\mathrm{mL}$ ) to pilot-scale simulant tests (resin bed volume: $1 \mathrm{~L}$ ). The superficial velocities studied span the range of velocities planned for the radioactive and simulant tests. The residence time, i.e., time that the liquid is in contact with the resin, is the same for the small-scale radioactive and large-scale simulant tests, as well as the design basis for the full-scale waste treatment plant.. The intermediate-scale tests allow evaluation of the effects of residence time, superficial velocity, and path length by varying the feed flow 


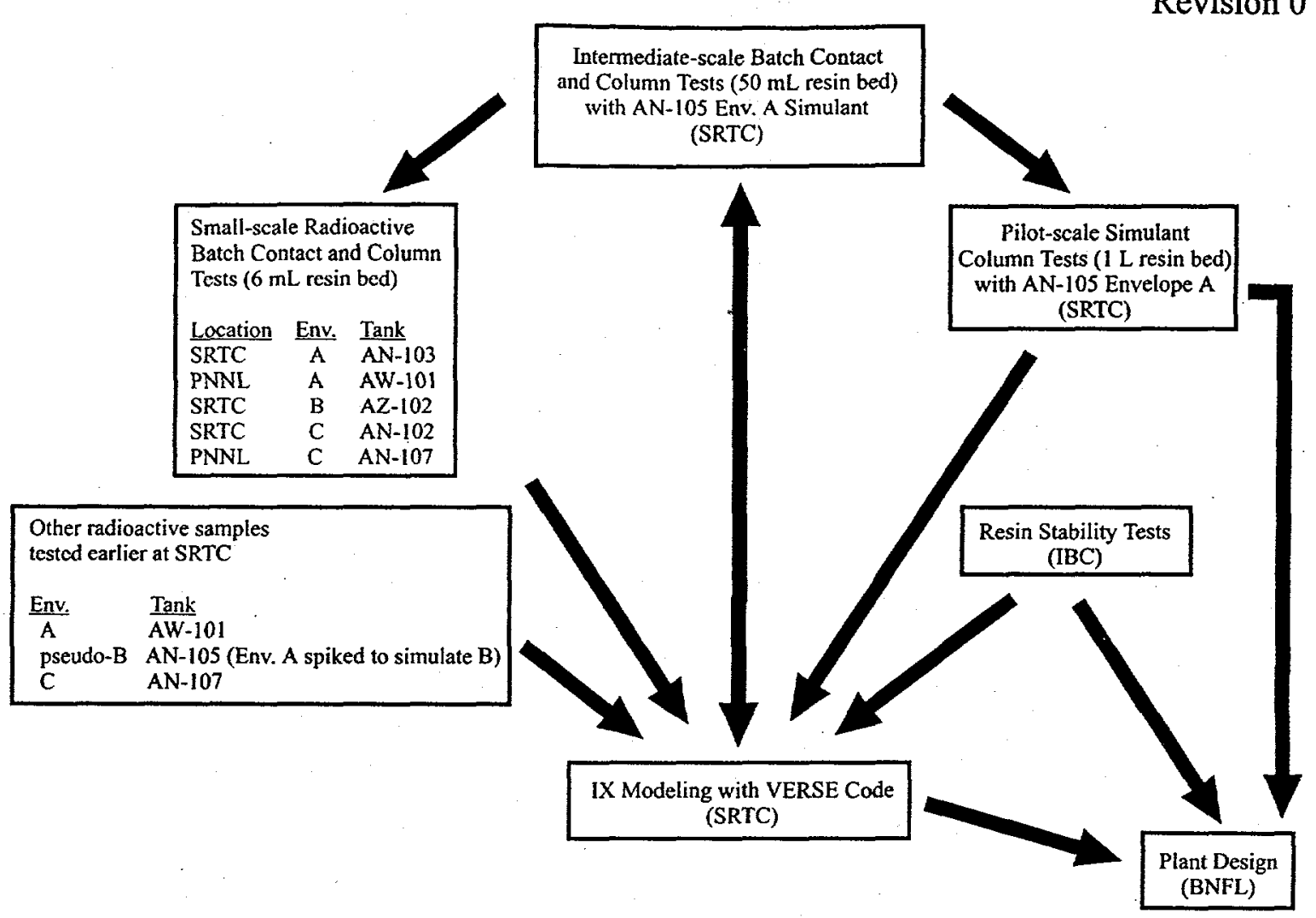

Figure 1. SuperLig ${ }^{\circledR}$ Ion Exchange Resin Testing Summary - SRTC $=$ Savannah River Technology Center, Aiken, SC; PNNL = Pacific Northwest National Laboratory, Richland, WA; BNFL = British Nuclear Fuels Limited, Inc., Richland, WA; IBC = IBC Advanced Technologies, American Fork, UT; VERSE = ion exchange modeling program available from Prof. Linda Wang, Purdue University.

rate and resin bed geometry, respectively. In addition, the equilibrium capacities of the resin batches were determined to evaluate production batch variability. The rhenium equilibrium batch contact and column data serve as a basis set for the development of an ion exchange model to predict SuperLig ${ }^{\circledR} 639$ column performance in large-scale plant operations designed for the removal of technetium from actual waste solutions. Data from the small-scale radioactive and pilot-scale simulant tests will be used to further refine the model. Results of this modeling will be available in future reports. Another important objective of this work was to determine the appropriate fluid to use for column elution.

Use of perrhenate ion to mimic pertechnetate ion has been previously studied. ${ }^{2}$ While the two ions are not identical, they are sufficiently similar to provide a basis for comparison. The tetrahedral geometries of oxygen atoms in these two species result in nearly identical ion sizes. All isotopes of technetium are radioactive, and use of rhenium as a nonradioactive substitute is significantly less expensive and generates no radioactive waste. 


\subsection{EXPERIMENTAL}

\subsection{Materials}

Three batches of SuperLig ${ }^{\circledR} 639$ resin were received from IBC Advanced Technologies, American Fork, Utah. All resin samples were composed of tan, spherical beads and were very similar in appearance. Some physical data reported in an earlier document for the 639 resins is provided in Table $1 .^{3}$ Batch contact tests were conducted for all three resin batches. Most of the column experiments were conducted using the highest density batch of resin (\#980624001DC). One additional test was conducted using an equal volume mixture of the two remaining batches.

Table 1. Physical characteristics of "as received" SuperLig ${ }^{\circledR} 639$ resins

\begin{tabular}{|c|c|c|c|}
\hline Batch \# & $\begin{array}{c}\text { Resin particle } \\
\text { density }(\mathrm{g} / \mathrm{mL})\end{array}$ & $\begin{array}{c}\text { Bulk dry density } \\
(\mathrm{g} / \mathrm{mL})\end{array}$ & $\begin{array}{c}\text { Water content } \\
(\%)\end{array}$ \\
\hline 980624001DC & 1.219 & 0.489 & 1.4 \\
\hline 981015DHC720011 & 1.147 & 0.468 & 1.3 \\
\hline 990420DHC720067 & $-\cdots--$ & 0.479 & $-\cdots$ \\
\hline
\end{tabular}

The Envelope A simulant composition given in Table 2 was based on Hanford Tank 241AN-105. The target composition contains approximately $5.0 \mathrm{M}\left[\mathrm{Na}^{+}\right], 1.3 \mathrm{M}\left[\mathrm{NO}_{3}{ }^{-}\right]$, and 1.6 M Free $\left[\mathrm{OH}^{-}\right]$. The simulant was prepared in $2-\mathrm{L}$ batches and allowed to sit overnight before being filtered through a 0.45 micron Nalgene ${ }^{\circledR}$ nylon filter. For the column experiments, numerous $2-\mathrm{L}$ batches of simulant were composited in a large carboy. The simulant was periodically inspected and refiltered when solids were observed. The measured simulant density was $1.23 \mathrm{~g} / \mathrm{mL}$. In column experiments, the first $750 \mathrm{~mL}$ of simulant exiting the column was discarded and the remainder of the solution was reused for subsequent tests after respiking the solution with sodium perrhenate. The first $750 \mathrm{~mL}$ of simulant was discarded because it contained approximately $1 \mathrm{BV}$ of sodium hydroxide solution, which, if mixed with the effluent simulant, would have changed the composition and prevented reuse for subsequent experiments. Freshly-prepared $2 \mathrm{~L}$ batches of simulant were added to maintain the volume needed to complete subsequent experiments. The density of the composited simulant was measured periodically to confirm that the bulk composition had not changed significantly. All solutions were prepared using ACS certified, high-purity reagents from Fisher Scientific, Inc. Analysis of the composited simulant prior to use confirmed the basic composition given in Table 2 . 
Table 2. 241-AN-105 Env. A Simulant Composition

\begin{tabular}{|c|c|}
\hline Chemical & Molarity \\
\hline $\mathrm{NaNO}_{3}$ & 1.16 \\
\hline $\mathrm{KNO}_{3}$ & 0.09 \\
\hline $\mathrm{NaNO}_{2}$ & 1.13 \\
\hline $\mathrm{NaOH}$ & 1.62 \\
\hline $\mathrm{NaAlO}_{2}$ & 0.69 \\
\hline $\mathrm{NaCl}$ & 0.12 \\
\hline $\mathrm{Na}_{2} \mathrm{CO}_{3}$ & 0.10 \\
\hline $\mathrm{Na}_{2} \mathrm{SO}_{4}$ & $3.8 \mathrm{E}-03$ \\
\hline $\mathrm{Na}_{3} \mathrm{PO}_{4}$ & 0.003 \\
\hline $\mathrm{Na}_{2} \mathrm{SiO}_{3}$ & 0.004 \\
\hline $\mathrm{K}_{2} \mathrm{MoO}_{4}$ & $4.02 \mathrm{E}-4$ \\
\hline $\mathrm{NaReO}_{4}$ & $7.4 \mathrm{E}-05$ \\
\hline $\mathrm{H}_{3} \mathrm{BO}_{3}$ & 0.002 \\
\hline $\mathrm{NaHCOO}$ & 0.03 \\
\hline $\mathrm{NaCH}_{3} \mathrm{COO}$ & 0.02 \\
\hline $\mathrm{Na}_{2} \mathrm{C}_{2} \mathrm{O}_{4}$ & 0.003 \\
\hline $\mathrm{HOCH}_{2} \mathrm{COOH}$ & 0.01 \\
\hline
\end{tabular}

Note: The average Tc-99 concentration reported for the actual AN-105 sample tested at SRTC was $4.4 \mathrm{E}-05 \mathrm{M}^{5}$

\subsection{Equipment and Procedures}

\subsubsection{Batch Contact Experiments}

Batch contact tests were performed in duplicate at ambient temperature using a Thermolyne orbital shaker. In a typical experiment ion exchange resin $(0.10-0.19 \mathrm{~g})$ and simulant $(10-19 \mathrm{~mL})$ were transferred to a $21 \mathrm{~mL}$ polyethylene vial and placed on the shaker. The ratio of solution volume to exchanger mass was typically $100 \pm 5$. The temperature was measured at the beginning and the end of each experiment (observed range: $19-22^{\circ} \mathrm{C}$ ). After $24 \pm 0.5$ hours, samples were removed from the shaker and visually inspected. In all cases the resin appeared to be intact indicating that agitation of the vials during the test did not lead to significant material degradation. The amounts of resin floating, suspended and sinking were recorded for each sample. The solution was then filtered through a 0.45 micron Nalgene ${ }^{\circledR}$ nylon filter using vacuum. Portions $(2-4$ $\mathrm{mL}$ ) of the filtrate and similarly-treated samples of the feed solutions (blanks) were analyzed for rhenium by the Savannah River Technology Center Analytical Development Section using ICP-MS. Data for the batch contact tests are provided in Attachment 1. 
Re distribution coefficients and \% removal were calculated for each experiment using the formulas shown in Eqs. 1 and 2, respectively.

$$
\begin{aligned}
& \mathrm{K}_{\mathrm{d}}=\left[\left(\mathrm{C}_{\mathrm{i}} / \mathrm{C}_{\mathrm{f}}\right)-1\right]\left[\mathrm{V} /\left(\mathrm{M}^{*} \mathrm{~F}\right)\right] \\
& \% \text { removal }=\frac{(100)^{*}\left(\mathrm{C}_{\mathrm{i}}-\mathrm{C}_{\mathrm{f}}\right)}{\mathrm{C}_{\mathrm{i}}} \\
& \mathrm{C}_{\mathrm{i}}=\text { initial }[\mathrm{Re}] \text { in feed }(\mathrm{mg} / \mathrm{L}) \\
& \mathrm{C}_{\mathrm{f}}=\text { final }[\mathrm{Re}] \text { after contact }(\mathrm{mg} / \mathrm{L}) \\
& V=\text { volume of solution used }(\mathrm{mL}) \\
& M=\text { mass of "as-received" resin }(\mathrm{g}) \\
& \mathrm{F}=\text { resin dry weight correction factor }
\end{aligned}
$$

F-factors were determined at SRTC to be $98.6 \%$ for batch \#980624001DC and $98.7 \%$ for batch \#981015DHC720011 (Table 1). An average F-factor of $98.7 \%$ was used to calculate the distribution coefficient for batch \#990420DHC720067 since the water content for this batch was not measured.

\subsubsection{Column Experiments}

Figure 2 shows the ion exchange column design. Columns were constructed from 2.7 and $4.0 \mathrm{~cm} \mathrm{ID} \mathrm{sodium} \mathrm{borosilicate} \mathrm{glass} \mathrm{tubing.} \mathrm{Decals} \mathrm{were} \mathrm{affixed} \mathrm{to} \mathrm{the} \mathrm{outer} \mathrm{walls} \mathrm{of}$ the columns with $1 \mathrm{~mm}$ graduations to measure the resin bed height. The outsides of the columns were coated with a layer of polyvinylchloride to reduce hazards associated with potentially pressurizing the apparatus. A 3-way, $6 \mathrm{~mm}$ bore Teflon ${ }^{\otimes}$ stopcock (\#1) was attached to the bottom of the columns. The column head was attached to the column using a Rudivis ground-glass joint. Two 2-way, $6 \mathrm{~mm}$ bore stopcocks (\#2 and \#3) were attached on opposite sides of the column head to serve as feed ports. The column head also contained a pressure gauge, a pressure relief valve, and a fill reservoir that also served as a vent. Stainless steel wire screens ( $200 \mathrm{mesh}$ ) were inserted into the columns to support the ion exchange resin. Colder Products Company polypropylene quickdisconnect couplings were used to connect low-density polyethylene tubing (11/64" ID) to the columns. All solutions were passed through the columns in the downflow direction using Fluid Metering Incorporated QG150 positive displacement pumps with $1 / 4$ " and $3 / 8$ " piston sizes. Samples were collected either manually or using a Spectrum Chromatography IS-95 Interval Sampler. 
BNF-003- 98-0140

Revision 0

Figure 2. Ion Exchange Column Design

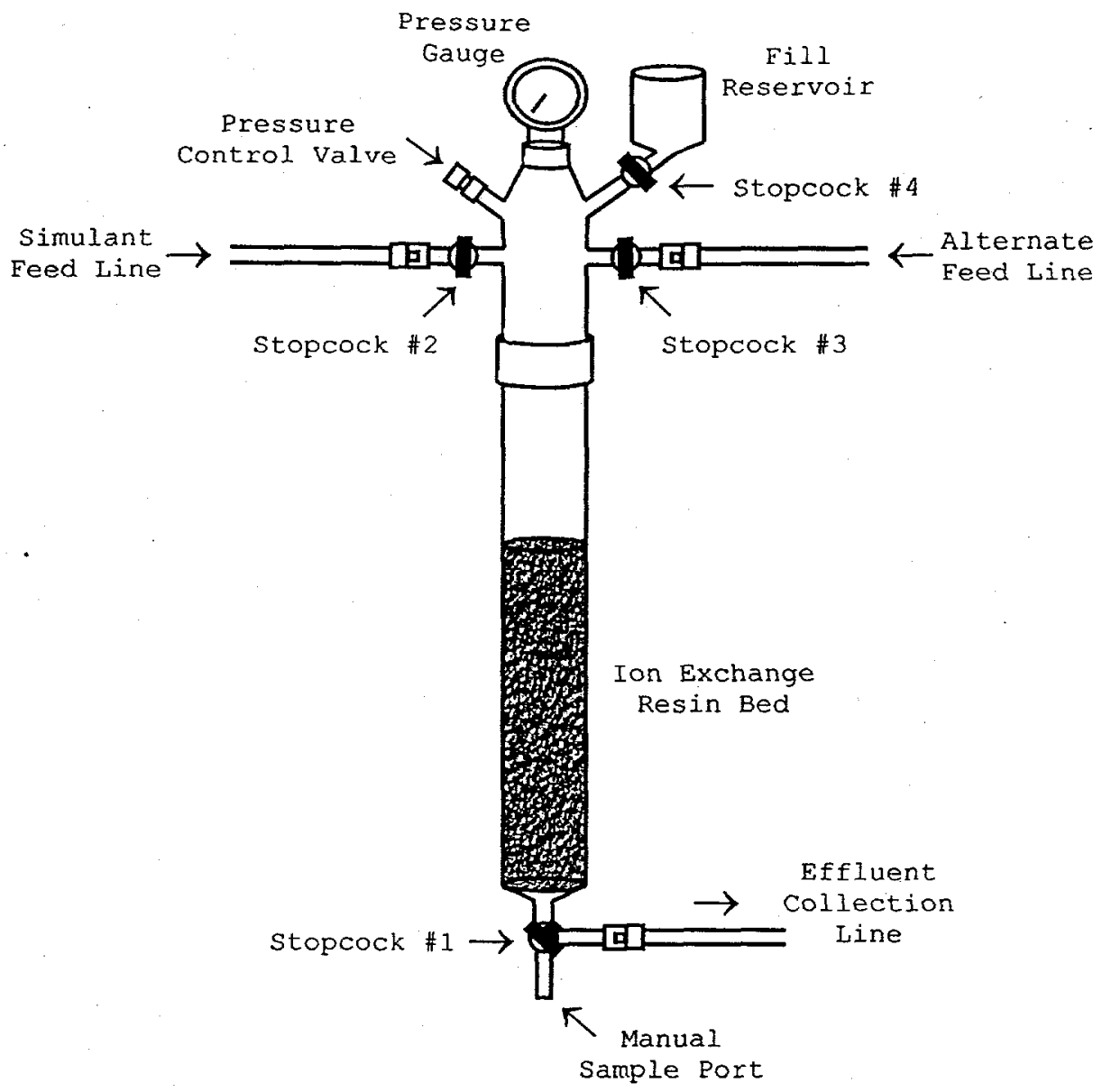

The ion exchange column was prepared by soaking the "as-received" resin overnight in deionized water and transferring the resin into the column as a suspension. For most experiments, a $51 \mathrm{~mL}$ sample of resin from batch \#980624001DC was used. An additional experiment was completed using $50 \mathrm{~mL}$ of a 50:50 mixture of batches 981015 DHC 720011 and 990420DHC720067 in order to model the pilot-scale column tests which were conducted using the same mixture of batches. In each experiment, the resin bed volume was determined by multiplying the measured height of the resin bed by the cross-sectional area. The temperature during the column experiments ranged from $20-23^{\circ} \mathrm{C}$. The bed was pretreated with 3 bed volumes of $1.0 \mathrm{M} \mathrm{NaOH}$ over a 1 hour period just prior to beginning each experiment (Pretreatment Cycle). The $\mathrm{NaOH}$ liquid level was adjusted so that the volume of liquid above the resin bed was approximately 50 $\mathrm{mL}$ ( 1 bed volume) before simulant solution was pumped into the column. Simulant (13$16 \mathrm{mg} / \mathrm{L}$ [Re]) was pumped into the column and approximately $8 \mathrm{~mL}$ samples of effluent were collected every 10-20 bed volumes (Feed Cycle). The liquid in the column was then drained to within approximately $1 \mathrm{~cm}$ of the top of the resin bed. Sodium hydroxide solution $(0.1 \mathrm{M})$ was pumped into the column until the volume of liquid above the resin bed was approximately $50 \mathrm{~mL}$. The exit line was opened and $2.5-3.5$ bed volumes of 0.1 
$\mathrm{M} \mathrm{NaOH}$ was passed through the column in one hour and samples of the effluent were collected every 20 minutes ( $\mathrm{NaOH}$ Wash Cycle). Subsequently, 2.5-3.5 bed volumes of deionized water were passed through the column in one hour and samples of the effluent were collected every 20 minutes (Post-Feed Water Wash Cycle). (Note: The water wash cycle served to displace residual sodium hydroxide solution from the column prior to elution.) The column was eluted with either deionized water or $0.5 \mathrm{M} \mathrm{HNO}_{3}$ at a flow rate of 1 or 3 bed volumes per hour and samples were collected every 1-2 hours (Elution Cycle). When eluting with acid, the liquid in the column was drained to within approximately $1 \mathrm{~cm}$ of the top of the resin bed following the elution cycle. Deionized water was pumped into the column until the volume of liquid above the resin bed was approximately $50 \mathrm{~mL}$. The column was washed with 3 bed volumes of deionized water during a 1 hour period (Post-Elution Water Wash Cycle). Feed and effluent samples were analyzed for rhenium by the Savannah River Technology Center Analytical Development Section using ICP-MS or ICP-ES. Data from the column experiments are provided in Attachment 2.

The flow rate was monitored during the column experiments by periodically measuring the time required to collect 10 or $25 \mathrm{~mL}$ of effluent. The effluent solution during the feed cycle was collected in 3-4 separate reservoirs. The total volume of effluent in each reservoir was measured and corrected for the volume of samples collected and the flow rate was calculated from the time of collection. The overall flow rate was taken to be the weighted average of the flow rates calculated for each collection bottle. The flow rates for the pretreatment, wash, and elution cycles were calculated from the time of collection and the volume of solution collected (after correction for the volume of samples collected). Flow rates measured during each experiment for the feed, wash and elution cycles are provided in Attachment 3. The number of bed volumes of solution processed at each sampling period during column operation was calculated from the frequency of collection and the flow rate. (Note: The column operating procedure was designed to emulate the actual plant operation, where the column is half full of resin and half full of liquid. According to the procedure, the initial simulant that was fed into the ion exchange column during the loading cycle was to be diluted by the $1 \mathrm{BV}$ of $1.0 \mathrm{M} \mathrm{NaOH}$ pretreatment solution which remained above the resin bed. Likewise, the post-feed water wash and the eluting solutions were allowed to mix with the liquid head left above the resin from the previous cycle. No attempt was made to correct for mixing of solutions in the column head-space when calculating the number of bed volumes of feed, wash, or eluate processed. Each cycle was considered to start at the moment that the feed line was transferred to the new feed bottle and the pump was activated.) The resin bed volume was monitored throughout the experiments by periodically measuring the height of the bed. The volume varied by less than $5 \%$ throughout the experiments.

\subsection{RESULTS AND DISCUSSION}

\subsection{Batch Contact Experiments}

Batch contact tests were conducted for three batches of SuperLig ${ }^{\otimes} 639$ resin at rhenium feed concentrations ranging from 0.25 to $225 \mathrm{mg} / \mathrm{L}$. All tests for which the initial 
rhenium concentration was below $5 \mathrm{mg} / \mathrm{L}$ were recontact tests in which the filtrate from earlier contact tests served as the feed solution. The resin particle densities measured for the SuperLig ${ }^{\circledR} 639$ batches ranged from 1.15 to $1.22 \mathrm{~g} / \mathrm{mL}^{3}$ while the density of $5 \mathrm{M}$ $\left[\mathrm{Na}^{+}\right]$Envelope A simulant was approximately $1.23 \mathrm{~g} / \mathrm{mL}$. Close inspection of the samples at the conclusion of the batch contact tests revealed that some resin batches tend to float in the test solution. Varying amounts $(0-50 \%)$ of the resin were observed to float in the solution, depending on the batch of resin being tested.

Distribution coefficients $\left(\mathrm{K}_{\mathrm{d}}\right)$ provide a quantitative measure of ion exchange resin equilibrium capacity. As shown in Table 3 and Figure 3, the observed rhenium distribution coefficients varied significantly depending on the resin batch. The $\mathrm{K}_{d}$ values measured for each batch at approximately $7 \mathrm{mg} / \mathrm{L}$ initial [Re] indicate that the resin capacity varies by a factor of 2.5 with batch \#980624001DC exhibiting the lowest capacity $(199 \mathrm{~mL} / \mathrm{g})$ and batch \#990420DHC720067 exhibiting the highest $(512 \mathrm{~mL} / \mathrm{g})$. The shapes of the adsorption isotherms in Figure 3 are typical of Langmuir-type adsorption. In general, the distribution coefficients increase as the rhenium equilibrium concentration in solution decreases. At very low concentrations the equilibrium capacity may begin to decrease again as shown in the adsorption curve for batch \#981015DHC720011. For each resin which was tested at various rhenium feed concentrations, the $K_{d}$ values seemed to plateau across a range of rhenium equilibrium concentrations. At final rhenium concentrations ranging from 0.7 to $25 \mathrm{mg} / \mathrm{L}$ the distribution coefficients for batch \#980624001DC were near $200 \mathrm{~mL} / \mathrm{g}$. At rhenium final concentrations ranging from 0.2 to $1.5 \mathrm{mg} / \mathrm{L}$ the distribution coefficients for batch \#981015DHC720011 were approximately $400 \mathrm{~mL} / \mathrm{g}$. Relative to batch \#980624001DC the plateau observed in the adsorption isotherm for batch \#981015DHC720011 was not observed until the rhenium equilibrium concentration was considerably lower (1.5 versus $25 \mathrm{mg} / \mathrm{L}$ final [Re]). (Note: The $\mathrm{K}_{d}$ value measured for batch \#980624001DC with a . final equilibrium concentration of $3.37 \mathrm{mg} / \mathrm{L}$ was anomalous presumably due to experimental or analytical error.) The trends observed in the equilibrium capacities of the resin batches do not correlate with the amount of resin observed to float in the simulant solution. Only batch \#981015DHC720011 exhibited a significant tendency to float (30$50 \%$ floating) in the simulant at the conclusion of the batch contact tests. As shown in Figure 3, the measured $\mathrm{K}_{d}$ 's for this resin batch were intermediate in magnitude relative to the remaining batches. This observation indicates that sufficient contact was obtained between the solid and the solution in all tests. The amount of resin observed to float in the batch contact tests is also consistent with the resin density measurements shown in Table 3. 
Table 3. Rhenium Distribution Coefficients $\left(K_{d}\right)$ Measured for SuperLig ${ }^{\circledR} 639$ Resin Batches

Batch \# 990420DHC720067

Initial $[\mathrm{Re}](\mathrm{mg} / \mathrm{L}) \quad$ Final $[\mathrm{Re}](\mathrm{mg} / \mathrm{L}) \quad \operatorname{Re} \mathrm{K}_{\mathrm{d}}(\mathrm{mL} / \mathrm{g}) \% \operatorname{Re}$ Removal \% resin floating 7.18 1.16 512 83.9 0

\section{Batch \# 981015DHC720011}

Initial [Re] (mg/L) Final [Re] (mg/L) Re $\mathrm{K}_{d}(\mathrm{~mL} / \mathrm{g}) \%$ Re Removal \% resin floating

\begin{tabular}{|c|c|c|c|c|}
\hline 0.26 & 0.06 & 351 & 78.5 & 30 \\
\hline 1.41 & 0.26 & 420 & 81.3 & 50 \\
\hline 6.96 & 1.41 & 390 & 79.8 & --- \\
\hline 72.78 & 16.34 & 338 & 77.5 & $-\cdots$ \\
\hline
\end{tabular}

\section{Batch \# 980624001DC}

Initial [Re] (mg/L) Final [Re] (mg/L) Re $\mathrm{K}_{d}(\mathrm{~mL} / \mathrm{g}) \% \operatorname{Re}$ Removal \% resin floating

\begin{tabular}{|c|c|c|c|c|}
\hline 2.40 & 0.77 & 208 & 67.8 & 0 \\
\hline 7.18 & 2.40 & 199 & 66.6 & 10 \\
\hline 13.99 & 3.37 & 315 & 75.9 & 10 \\
\hline 69.17 & 24.61 & 181 & 64.4 & 10 \\
\hline 152.58 & 62.75 & 143 & 58.9 & 10 \\
\hline 222.70 & 102.62 & 117 & 53.9 & 0 \\
\hline
\end{tabular}

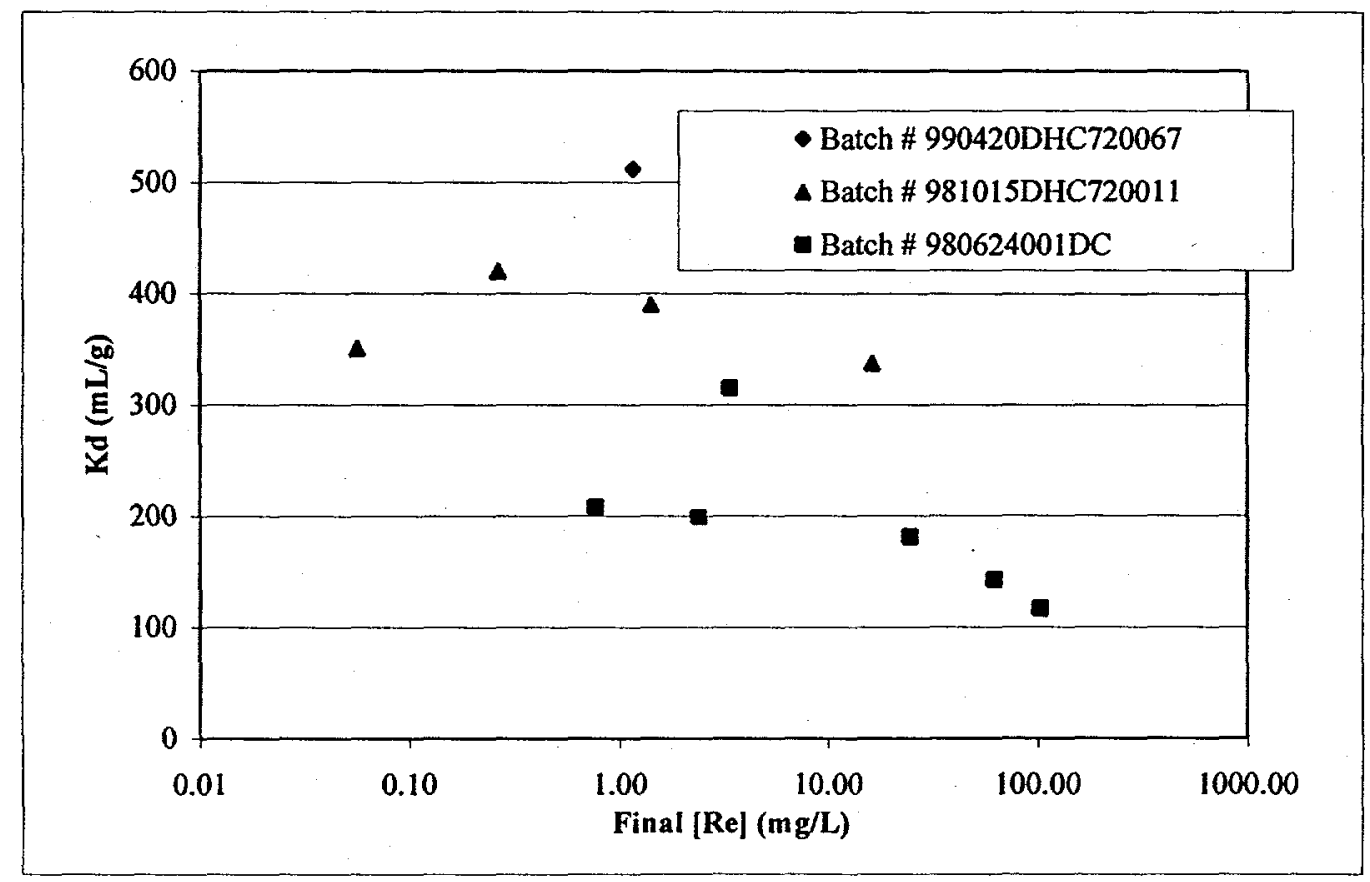

Figure 3. SuperLig ${ }^{\circledast 6} 639$ Batch Comparison - Final [Re] versus $K_{d}$ 


\subsection{Column Experiments}

Results for the four column experiments performed with SuperLig ${ }^{\circledR} 639$ batch \#980624001DC are shown in Table 4. Three of the four experiments were completed using a $2.7 \mathrm{~cm}$ ID column at different volumetric flow rates (Figure 4). The . breakthrough profiles follow the expected trends with faster flow rates resulting in more rapid rhenium breakthrough. Decreasing the flow rate from 73.4 to $3.4 \mathrm{BV} / \mathrm{hr}$ increases the $50 \%$ Re breakthrough point by a factor of 10 . In addition, the $50 \%$ Re breakthrough point of $90 \mathrm{BV}$ observed at a feed superficial velocity of $0.51 \mathrm{~cm} / \mathrm{min}$ is very near the value expected based on the batch contact data. The theoretical $50 \%$ Re breakthrough point can be predicted from $K_{d}$ data and the bulk resin density. At a rhenium feed concentration near $15 \mathrm{mg} / \mathrm{L}$ the estimated $R e K_{d}$ for batch $\# 980624001 D C$ is $200 \mathrm{~mL} / \mathrm{g}$. The vendor reports the wet bulk resin density for SuperLig ${ }^{\circledR} 639$ resin to be $0.4 \mathrm{~g} / \mathrm{mL}$. The bulk resin density for batch \#980624001DC was reported by SRTC to be 0.489 $\mathrm{g} / \mathrm{mL}{ }^{3}$ The number of bed volumes required to reach $50 \%$ breakthrough $(\lambda)$ can be calculated using Eqn. 3.

$$
\lambda=\left(\mathrm{K}_{\mathrm{d}}\right) \times \text { (bulk resin density) }
$$

The $\lambda$ value calculated for a feed concentration near $15 \mathrm{mg} / \mathrm{L}\left(\mathrm{K}_{d}=\sim 200 \mathrm{~mL} / \mathrm{g}\right)$ ranges from 80 to $98 \mathrm{BV}$ depending on the value used for the bulk resin density. The observed $50 \% \mathrm{Re}$ breakthrough point of $90 \mathrm{BV}$ falls within this range, indicating that $\mathrm{Re}$ adsorption onto the resin approaches the equilibrium capacity at $3 \mathrm{BV} / \mathrm{hr}$. Operating the plant at this flow rate would fully utilize the resin capacity to process the maximum volume of waste before reaching the $50 \%$ Re breakthrough point. The time required for column loading would be maximized and the frequency of elution and regeneration would be minimized relative to operating at faster flow rates. The maximum flow rate

Table 4. SuperLig ${ }^{\circledR} 639$ Column Re Breakthrough Summary

Batch \#980624001DC, $51 \mathrm{~mL}$ Resin Bed

\begin{tabular}{|c|c|c|c|c|}
\hline Experiment \# & $\begin{array}{c}\text { Bed Diameter/Height } \\
(\mathrm{cm})\end{array}$ & $\begin{array}{c}\text { Flow Rate } \\
(\mathrm{cm} / \mathrm{min})\end{array}$ & $\begin{array}{c}\text { Flow Rate } \\
(\mathrm{BV} / \mathrm{hr})\end{array}$ & $\begin{array}{c}50 \% \text { Breakthrough } \\
(\mathrm{BV})\end{array}$ \\
\hline 1 & $2.7 / 9.0$ & 0.51 & 3.4 & 90 \\
\hline 2 & $2.7 / 9.0$ & 5.2 & 34.7 & 30 \\
\hline 3 & $2.7 / 9.0$ & 11 & 73.4 & 9 \\
\hline 4 & $4.0 / 4.1$ & 0.48 & 6.9 & 55 \\
\hline
\end{tabular}

50:50 Mixture of Batches 981015DHC720011 and 990420DHC720067, 50 mL Resin Bed

\begin{tabular}{|c|c|c|c|c|}
\hline Experiment \# & $\begin{array}{c}\text { Bed Diameter/Height } \\
(\mathrm{cm})\end{array}$ & $\begin{array}{c}\text { Flow Rate } \\
(\mathrm{cm} / \mathrm{min})\end{array}$ & $\begin{array}{c}\text { Flow Rate } \\
(\mathrm{BV} / \mathrm{hr})\end{array}$ & $\begin{array}{c}50 \% \text { Breakthrough } \\
(\mathrm{BV})\end{array}$ \\
\hline 5 & $2.7 / 8.8$ & 0.43 & 2.9 & 150 \\
\hline
\end{tabular}

Note: Experiment numbers indicate the order of completion 


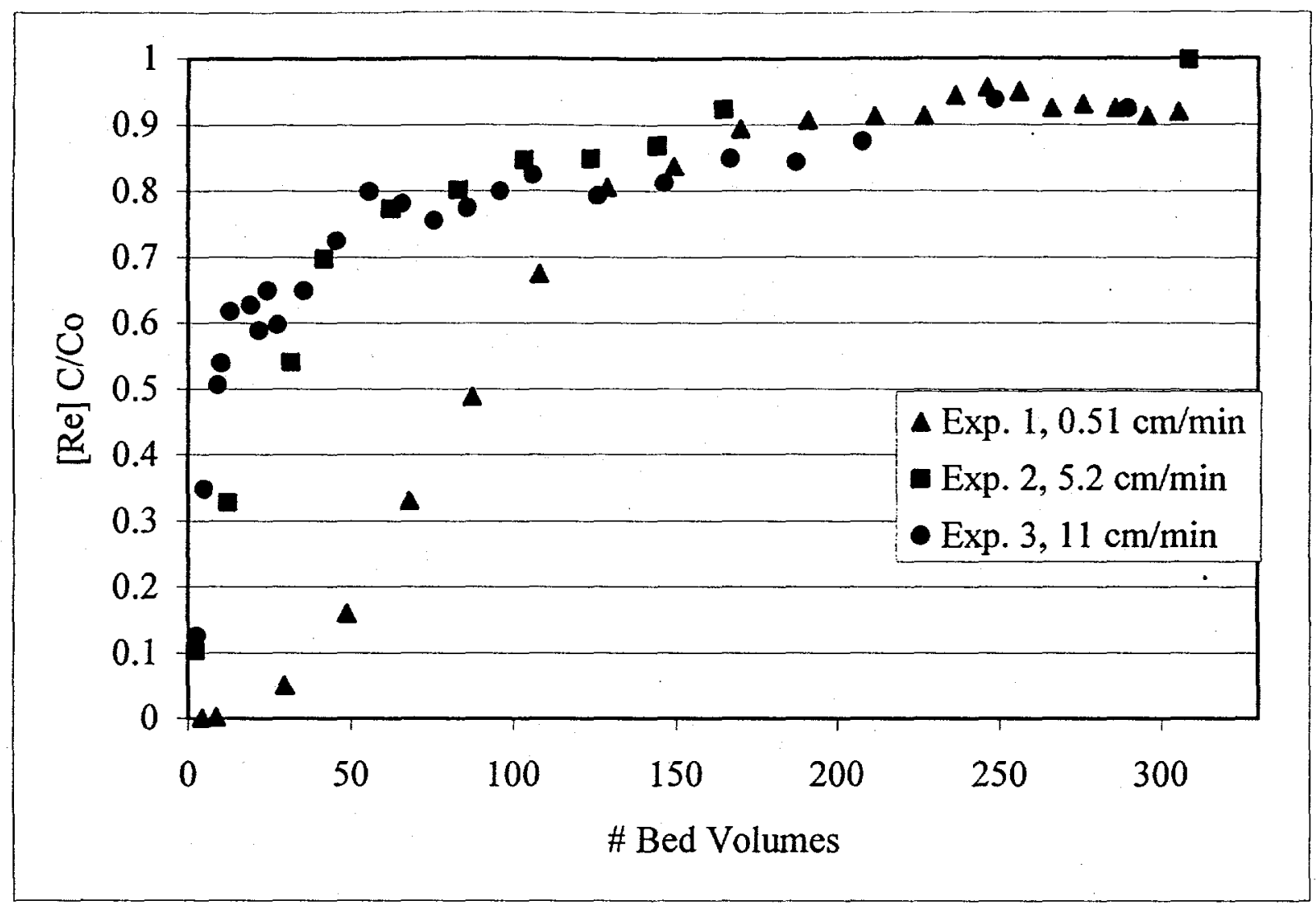

Figure 4. SuperLig ${ }^{\circledR} 639$ Batch \#980624001DC Rhenium Breakthrough Profiles (resin bed: $51 \mathrm{~mL}, 2.7 \mathrm{~cm} \mathrm{ID)}$

required to approach equilibrium conditions in the column should be generated by the ion exchange model which will be developed from the data reported herein.

Rhenium elution profiles for the three experiments performed with the $2.7 \mathrm{~cm}$ ID column are shown in Figures 4 and 5. In each case the maximum rhenium concentration was observed near the end of the water wash cycle (flow rate: $3 \mathrm{BV} / \mathrm{hr}$ ) and the tail of the elution profile extended into the elution cycle (flow rate: $1 \mathrm{BV} / \mathrm{hr}$ ). The profiles shown in Figures 4 and 5 start at the beginning of the water wash cycle. Experiments 1 and 3 utilized $0.5 \mathrm{M} \mathrm{HNO}_{3}$ as the eluent and deionized water was the eluent for experiment 2 . In each experiment the peak rhenium concentration was observed between 2-3 BV after the start of the water wash cycle. Acid significantly increases the volume of solution required to elute the column compared to water. The rhenium concentration in the eluate decreased to $<1 \%$ of the feed Re concentration within $28 \mathrm{BV}$ when eluting with acid and within $16 \mathrm{BV}$ when eluting with deionized water. (Note: Integration of the area above the loading curves for Experiments 2 and 3 in Fig. 4 indicated that Re loading on the column was nearly identical in these two experiments. Therefore, differences in $\mathrm{Re}$ loading on the column in these experiments does not explain the differences in the elution profiles discussed above.) 
Revision 0

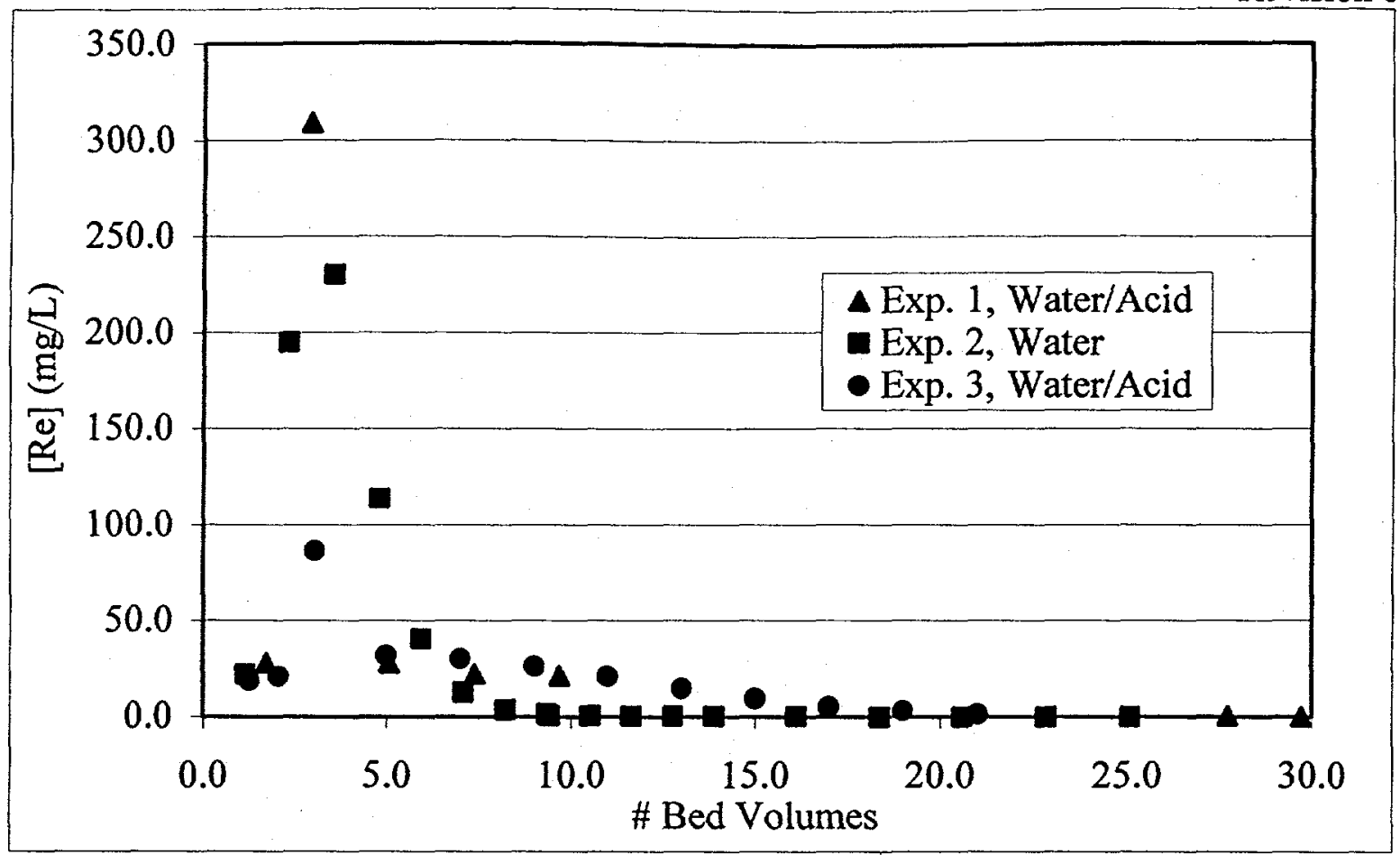

Figure 5. SuperLig ${ }^{\circledR} 639$ Batch \#980624001DC Elution Profiles (resin bed: $51 \mathrm{~mL}, 2.7$ $\mathrm{cm} \mathrm{ID;} \mathrm{0-3} \mathrm{BV} \mathrm{-} \mathrm{deionized} \mathrm{water} \mathrm{at} 3 \mathrm{BV} / \mathrm{hr} ; 4-30 \mathrm{BV}$ - water or $0.5 \mathrm{M} \mathrm{HNO}_{3}$ at 1 $\mathrm{BV} / \mathrm{hr}$ )

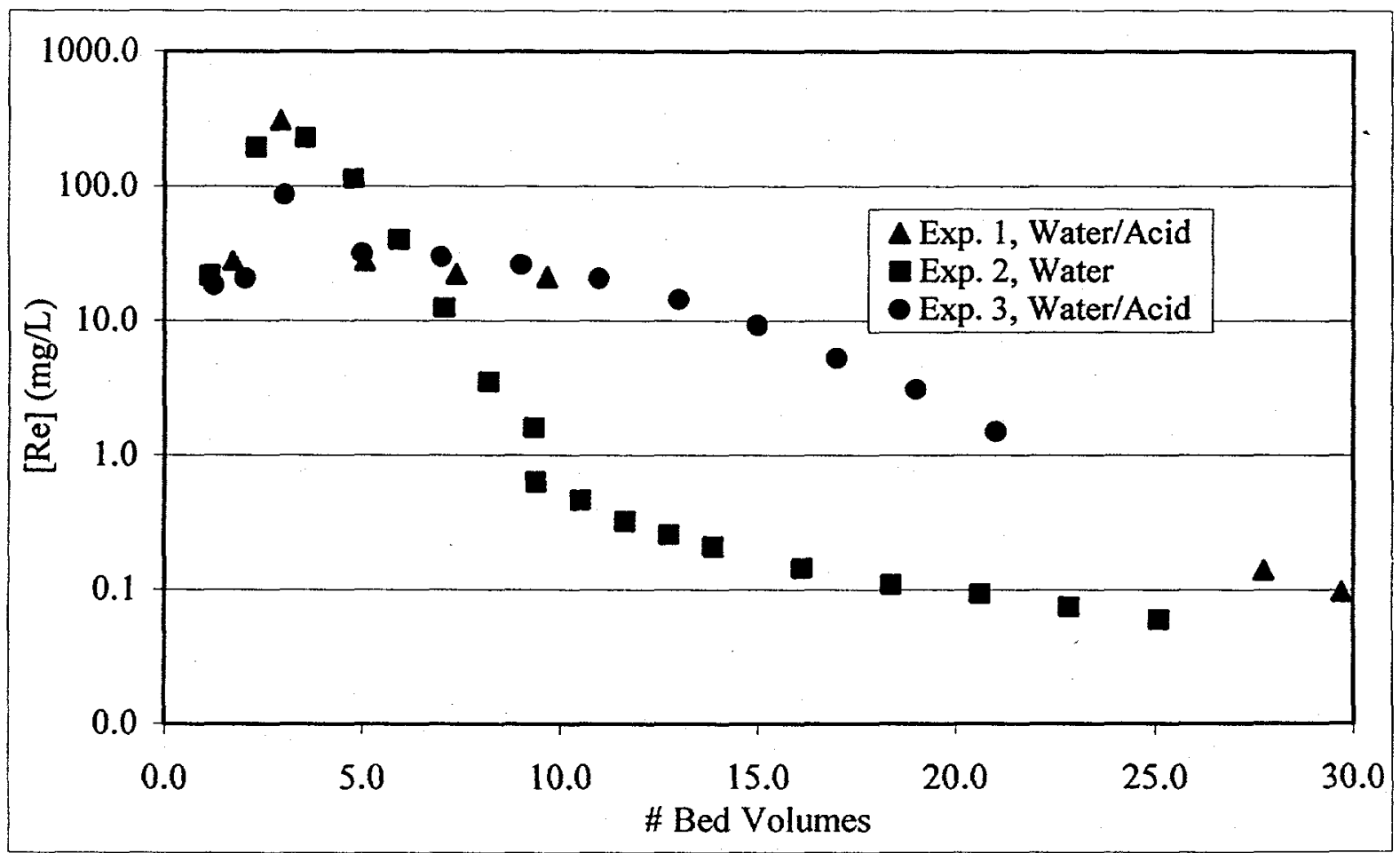

Figure 6. SuperLig ${ }^{\circledR} 639$ Batch \#980624001DC Elution Profiles - Semi-Log Plot (resin bed: $51 \mathrm{~mL}, 2.7 \mathrm{~cm} \mathrm{ID;0-3} \mathrm{BV} \mathrm{-} \mathrm{deionized} \mathrm{water} \mathrm{at} 3 \mathrm{BV} / \mathrm{hr} ; 4-30 \mathrm{BV}$ - water or $0.5 \mathrm{M}$ $\mathrm{HNO}_{3}$ at $1 \mathrm{BV} / \mathrm{hr}$ ) 
After completing three column experiments in the $2.7 \mathrm{~cm}$ ID column, the resin was transferred to a $4.0 \mathrm{~cm}$ diameter column (Exp. 4). A column experiment was performed at a feed superficial velocity of $0.48 \mathrm{~cm} / \mathrm{min}$, which is near the slowest velocity used in the smaller diameter column. During this experiment, it was initially quite difficult to maintain a stable liquid level above the resin during the feed cycle. These problems were not overcome until well into the experiment. On two occasions the liquid level fell below the top of the resin bed briefly. Once the liquid level was stabilized, no obvious air bubbles were observed within the bed. (Note: Floating of the resin bed was probably due to less extensive bridging of the resin beads in the $4.0 \mathrm{~cm}$ diameter column, although floating of the resin due to unseen trapped air bubbles cannot be ruled out.) As the simulant solution was passed through the resin bed a significant portion of the resin gradually began to float. After approximately 120 bed volumes of feed solution had passed through the column it was necessary to add quartz wool and glass beads to the top of the bed to keep the resin from floating. Figure 7 compares the rhenium breakthrough profiles observed for the experiments performed in the 2.7 and $4.0 \mathrm{~cm}$ ID columns at comparable superficial velocities. Increasing the column ID from 2.7 to $4.0 \mathrm{~cm}$ decreases the path length from $9.0 \mathrm{~cm}$ to $4.1 \mathrm{~cm}$. The volumetric flow rate was increased from 3.4 $(2.7 \mathrm{~cm}$ ID column) to $6.9 \mathrm{BV} / \mathrm{hr}$ in the $4.0 \mathrm{~cm}$ ID column in order to maintain approximately the same superficial velocity $(0.5 \mathrm{~cm} / \mathrm{min})$. The breakthrough profiles observed follow the expected trend. The Re $50 \%$ breakthrough point in the $4.0 \mathrm{~cm}$ ID column (55 BV) was $39 \%$ lower than the breakthrough observed in the smaller diameter column ( $90 \mathrm{BV})$. This result was expected since the residence time and path length were shorter in the larger diameter column.

The $4.0 \mathrm{~cm}$ diameter column was eluted with water at a superficial velocity of 0.19 $\mathrm{cm} / \mathrm{min}(2.7 \mathrm{BV} / \mathrm{hr}$ ) which was comparable to the superficial velocity of $0.16 \mathrm{~cm} / \mathrm{min}$ $(1.1 \mathrm{BV} / \mathrm{hr})$ used for the water elution in the $2.7 \mathrm{~cm}$ ID column. The elution profiles for the two experiments are shown in Figure 8. In general, the elution profile observed for the $4.0 \mathrm{~cm}$ ID column is similar to the profile observed in the $2.7 \mathrm{~cm}$ ID column. The maximum rhenium concentration is observed near $4 \mathrm{BV}$ and the width of the elution peak at half-height is comparable to the width observed for the $2.7 \mathrm{~cm}$ ID column. However, the elution tail for the experiment in the $4.0 \mathrm{~cm}$ ID column is considerably longer than was observed for the $2.7 \mathrm{~cm}$ ID column. In the larger diameter column, the Re concentration after $15 \mathrm{BV}$ of eluate had been collected was approximately $8 \%$ of the feed concentration. For comparison, in the smaller diameter column the Re concentration was $<1 \%$ of the feed concentration after $16 \mathrm{BV}$ of eluate had been collected. This observation indicates that residence time is an important processing parameter for rhenium elution. The residence time for the elution of the $4.0 \mathrm{~cm}$ ID column decreased relative to the 2.7 $\mathrm{cm}$ ID column due to the faster volumetric flow rate. Presumably, the shorter residence time resulted in a longer elution tail, despite the fact that the path length was shorter in the larger diameter column. 
Revision 0

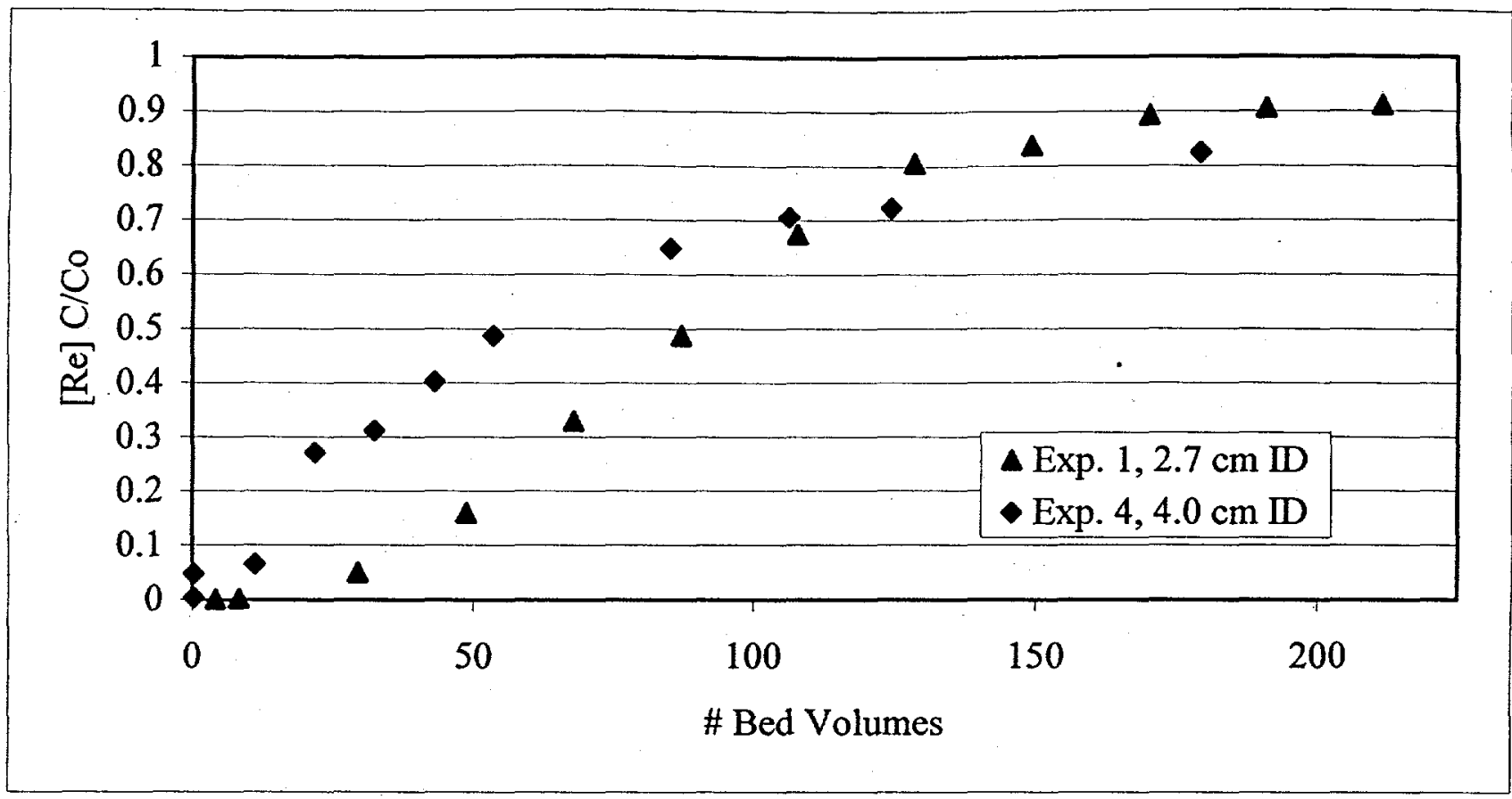

Figure 7. SuperLig ${ }^{\circledR} 639$ Batch \#980624001DC Rhenium Breakthrough Profiles Column L/D Comparison (resin bed: $51 \mathrm{~mL}$, superficial velocity: app. $0.5 \mathrm{~cm} / \mathrm{min}$ )

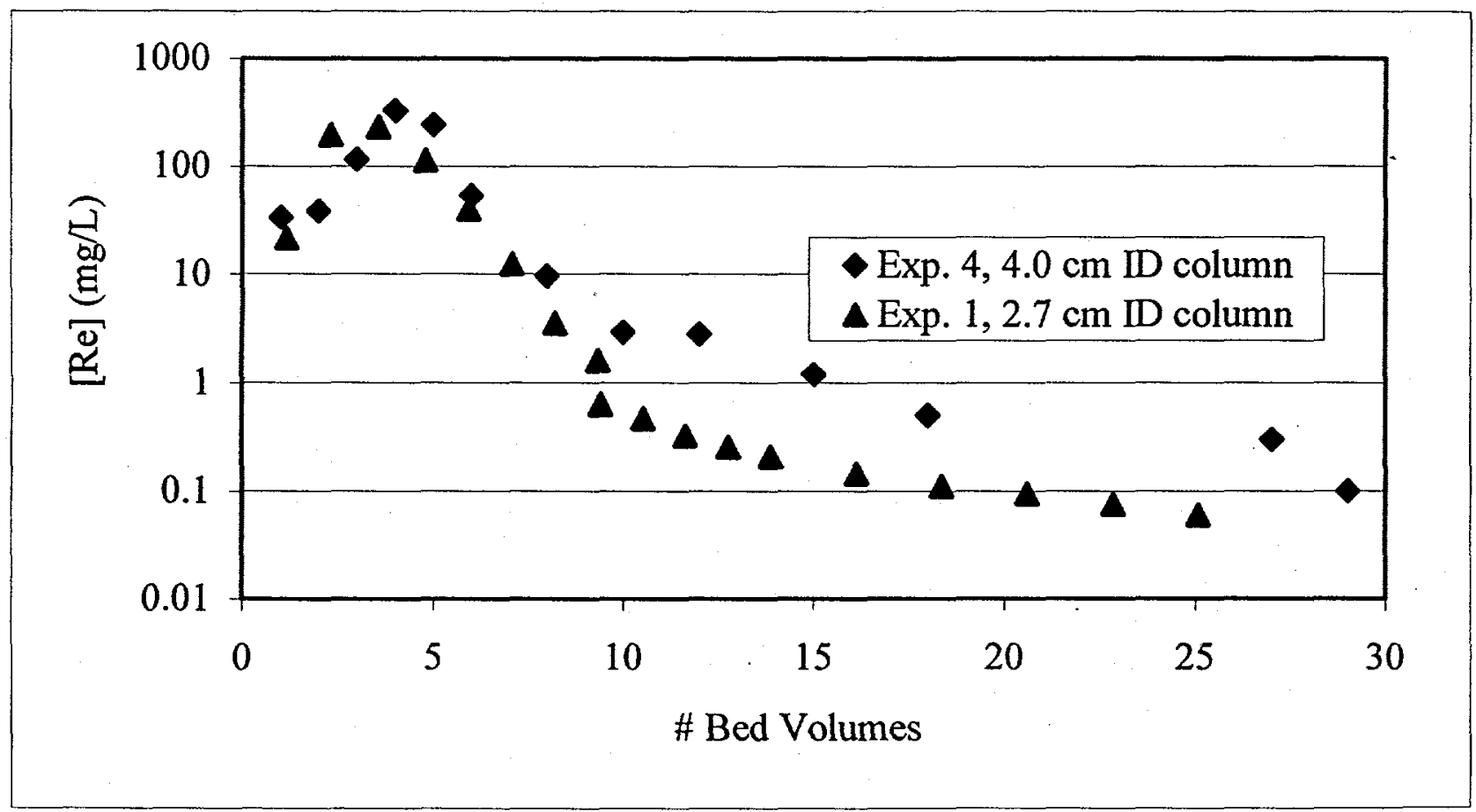

Figure 8. SuperLig ${ }^{\circledR} 639$ Batch \#980624001DC Water Elution Profiles - Column L/D Comparison (resin bed: $51 \mathrm{~mL} ; 4.0 \mathrm{~cm}$ ID Flow Rate: $0-30 \mathrm{BV}$ at $3 \mathrm{BV} / \mathrm{hr} ; 2.7 \mathrm{~cm} \mathrm{ID}$ Flow Rate: $0-3 \mathrm{BV}$ at $3 \mathrm{BV} / \mathrm{hr}, 3-30 \mathrm{BV}$ at $1 \mathrm{BV} / \mathrm{hr}$ ) 
A column experiment was also performed using a 50:50 mixture of SuperLig ${ }^{\circledR} 639$ resin batches 981015 DHC720011 and 990420DHC720067 (Exp. 5). This mixture is currently being used in larger, pilot-scale simulant tests at SRTC. The predicted Re $50 \%$ breakthrough point based on equation (1) is $213 \mathrm{BV}$ (estimated $\mathrm{Kd}$ at initial [Re] 15 $\mathrm{mg} / \mathrm{L}: 450$; Note: The $\mathrm{K}_{d}$ value was determined by extrapolating and averaging $\mathrm{K}_{d}$ data for both batches. The average bulk dry density for the mixture of resin batches 981015DHC720011 and 990420DHC720067 was $0.474 \mathrm{~g} / \mathrm{mL}$ based on the data presented in Table 1). The experiment was conducted in a $2.7 \mathrm{~cm}$ ID column at a flow rate of $2.9 \mathrm{BV} / \mathrm{hr}(0.43 \mathrm{~cm} / \mathrm{min})$, which is comparable to the slowest flow rate used for batch \#980624001DC. The breakthrough profile for the column containing a mixture of resin batches is compared in Figure 9 to the breakthrough profile for batch \#980624001DC at a similar flow rate. The Re 50\% breakthrough was observed at 150 $\mathrm{BV}$ for the mixture of batches, which is nearly twice the number of bed volumes at which breakthrough was observed for batch \#980624001DC (Re 50\% breakthrough: $90 \mathrm{BV}$ ). This result is qualitatively consistent with the distribution coefficient results.

Figure 10 shows the water elution profile observed for the mixture of resin batches. The column was eluted at $3 \mathrm{BV} / \mathrm{hr}(0.41 \mathrm{~cm} / \mathrm{min})$. The maximum rhenium concentration is observed near $5 \mathrm{BV}$. The rhenium concentration in the eluate was $22 \%$ of the feed concentration after $27 \mathrm{BV}$ of eluate had been collected. Since the adsorption capacities of batches $981015 \mathrm{DHC} 720011$ and $990420 \mathrm{DHC} 720067$ were significantly different from batch \#980624001DC, the elution data cannot be directly compared. However, it is apparent that elution of the mixture of resin batches 981015DHC720011 and $990420 \mathrm{DHC} 720067$ at a flow rate of $\sim 3 \mathrm{BV} / \mathrm{hr}$ results in a long elution tail. Based on observations regarding the effects of residence time on rhenium elution, elution at slower flow rates would be expected to decrease the volume of eluent required. 
Revision 0

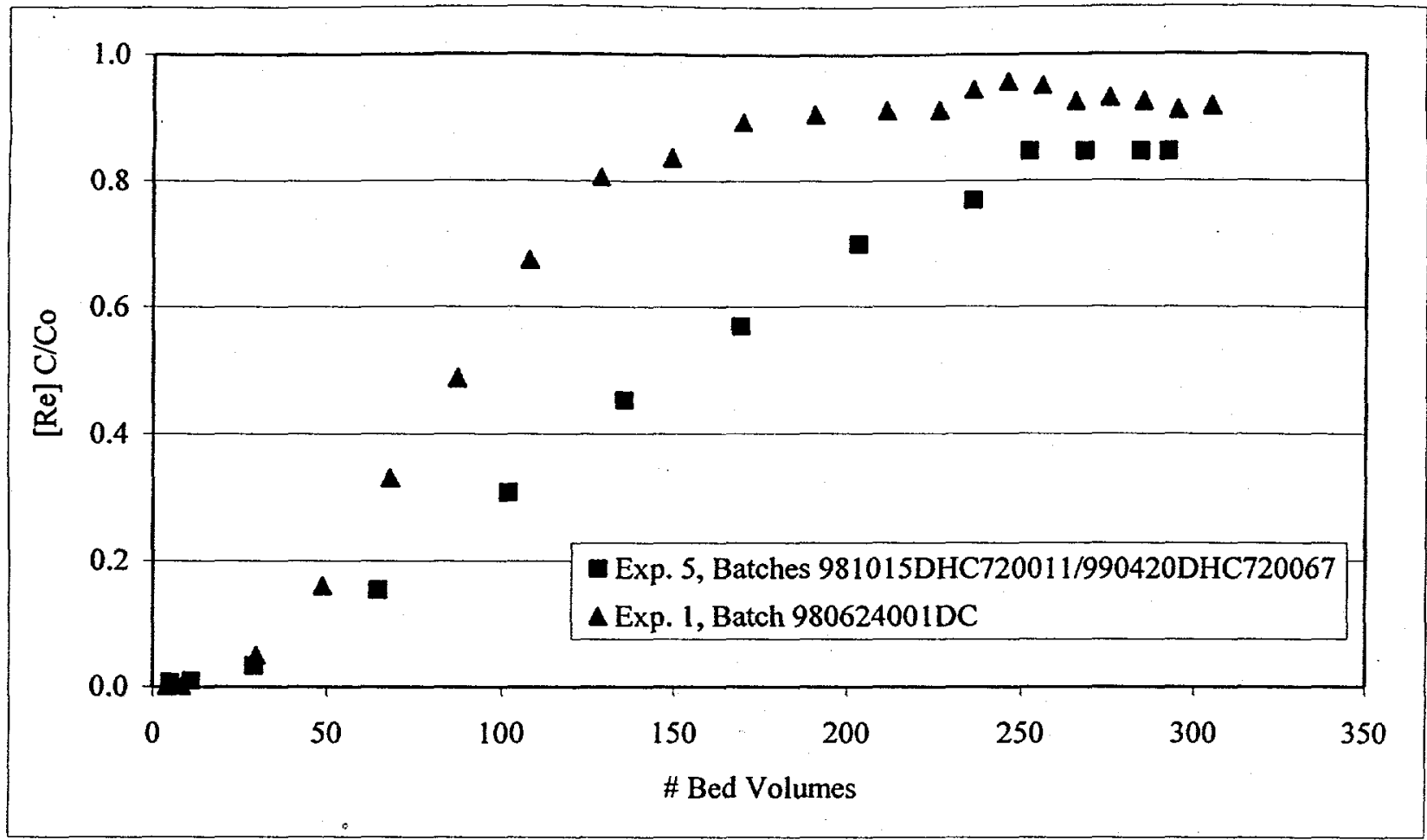

Figure 9. SuperLig ${ }^{\circledR} 639$ Rhenium Breakthrough Profiles - Batch Comparison (resin bed: $51 \mathrm{~mL}$ (Exp. 1) and $50 \mathrm{~mL}$ (Exp. 5); superficial velocity: $0.51 \mathrm{~cm} / \mathrm{min}$ (Exp. 1), 0.43 $\mathrm{cm} / \min (\operatorname{Exp} .5))$

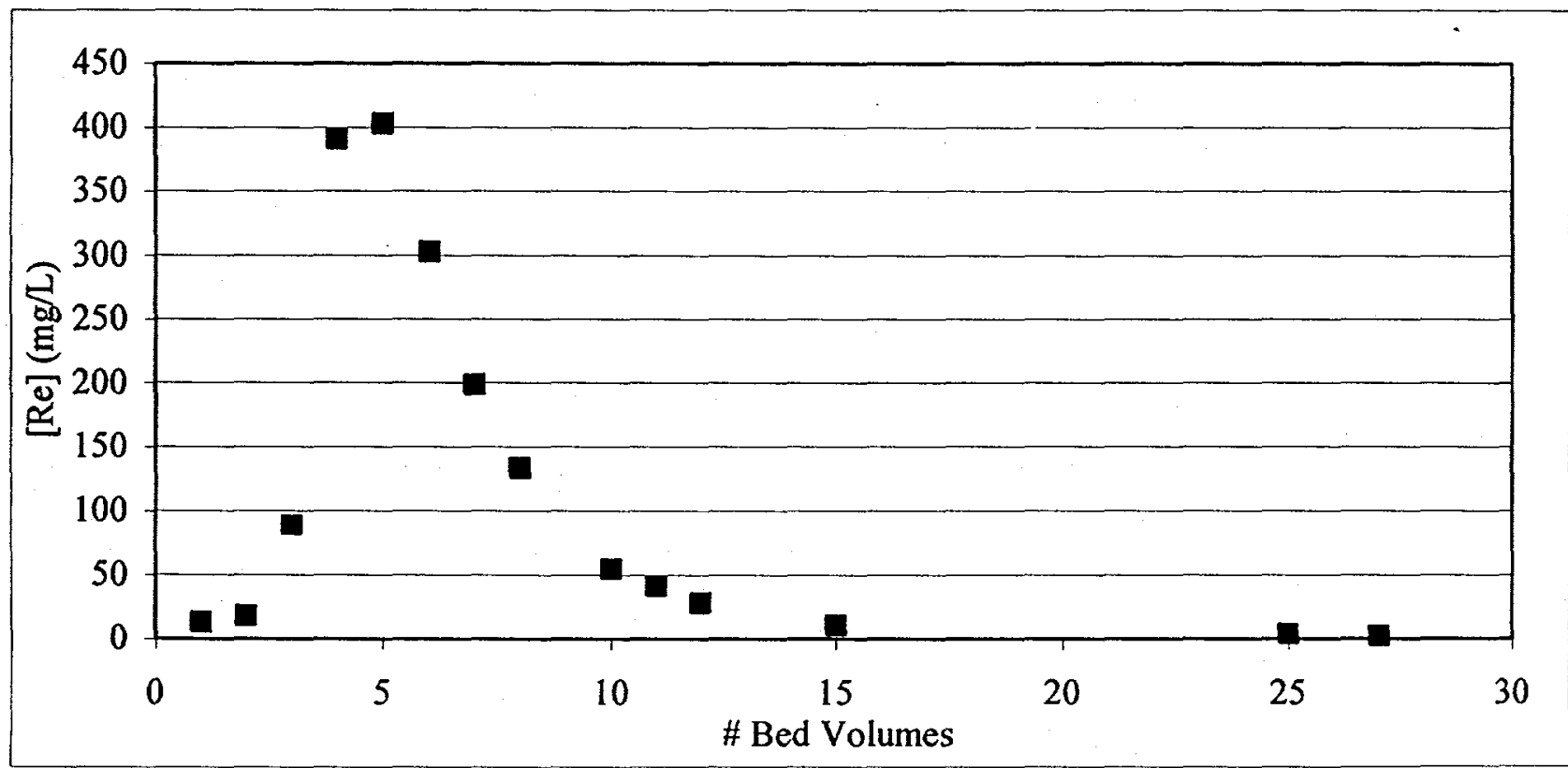

Figure 10. SuperLig ${ }^{\otimes} 639$ Water Elution Profile-Mixture of Batches 981015DHC720011 and 990420DHC720067 (resin bed: $50 \mathrm{~mL}, 2.7 \mathrm{~cm} \mathrm{ID}$; Flow Rate: 3 $\mathrm{BV} / \mathrm{hr})$ 


\subsection{CONCLUSIONS}

Simulant batch contact and column optimization tests have been completed on three batches of SuperLig ${ }^{\circledR} 639$ ion exchange resin. Consistent results were obtained for the batch contact and column tests. At feed flow rates near $3 \mathrm{BV} / \mathrm{hr}$ the column performance of all resin batches approached or exceeded the current plant design criteria, which requires a minimum of $100 \mathrm{BV}$ of feed to be processed prior to elution and regeneration. However, synthesis of the resin should be modified to increase the density to avoid floating the resin bed while processing these dense feed solutions. Additional research is also needed to identify the manufacturing variables that affect resin capacity and develop methods for its optimization. The columns were most effectively eluted with water at a flow rate of $1 \mathrm{BV} / \mathrm{hr}$. Further work is needed to evaluate methods for reducing column elution duration and volume. These may include heating the water used for elution (as recommended by IBC personnel) or periodically stopping the flow during the elution to allow the resin to continue to desorb technetium without generating more eluate volume.

\subsection{DESIGN CHECK}
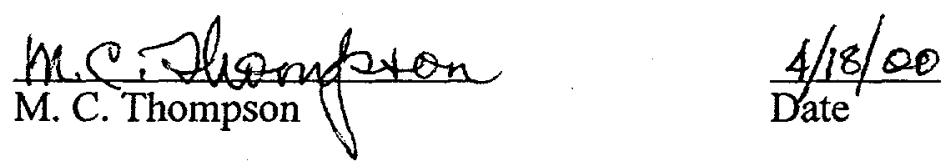

\subsection{APPROVALS}

Hanford Tank Waste Ion Exchange Column Optimization Task Technical and Quality Assurance Plan (U), BNF-003-98-0032, Rev. 0. 


\subsection{REFERENCES}

1. TWRS Privatization Contract No. DE-AC06-96RL13308, Part I, Section C.

2. Schroeder, N.C., Radzinski, S., Ball, J., Ashley, K., Cobb, S.L., Cutrell, B., Adams, J.M., Johnson, C., Whitener, G.D., Technetium Partitioning for the Hanford Tank Waste Remediation System: Anion Exchange Studies for Partitioning Technetium from Synthetic DSSF and DSS Simulants and Actual Hanford Wastes (101-SY and 103-SY) Using Reillex-HPQ Resin, FY95 Final Report, LA-UR-95-4440, Los Alamos National Laboratory.

3. Hassan, N. M.; King, W. D.; McCabe, D. J. SuperLig ${ }^{\circledR}$ Ion Exchange Resin Swelling and Bouyancy Study (U), BNF-003-98-0051, Rev. 0.

4. Russ Eibling Report, SRTC, Document \# not currently available.

5. Hassan, N. M.; McCabe, D. J. Hanford Envelope A Tank Waste Ion Exchange Column Study (U), SRTC-BNFL-019.

\section{DISTRIBUTION:}

M. E. Johnson, BNFL, Inc.

S. T. Wach, 773-42A

M. C. Thompson, 773-A

H. F. Sturm, 773-A

L. M. Nelson, 773-43A

J. L. Steimke, 786-5A

T. J. Steeper, 786-5A

D. Kurath, PNNL

BNFL Part B Document File, B. Skwarek, 773-41A

W. D. King, 773-42A

D. J. McCabe, 773-42A

N. M. Hassan, 773-A 


\subsection{APPENDIX}

\subsection{Attachment 1. SuperLig ${ }^{\circledR} 639$ Batch Contact Data.}

Batch \#980624001DC

\begin{tabular}{|c|c|c|c|c|}
\hline Sample \# & BNF-SSIX-17-7 & BNF-SSIX-17-7-D & BNF-SSIX-17-5 & BNF-SSIX-17-5-D \\
\hline LIMS \# & 300127273 & 300127274 & 300127269 & 300127270 \\
\hline Solution Mass (g) & 19.249 & 18.9075 & 22.022 & 22.0257 \\
\hline Resin Mass (g) & 0.1587 & 0.1573 & 0.1803 & 0.1803 \\
\hline Solution Volume $(\mathrm{mL})$ & 15.65 & 15.37 & 17.90 & 17.91 \\
\hline Initial [Re] (mg/L) & 2.37 & 2.42 & 7.18 & 7.18 \\
\hline Final $[\mathrm{Re}](\mathrm{mg} / \mathrm{L})$ & 0.788 & 0.752 & 2.37 & 2.42 \\
\hline solution volume/exchanger mass & 98.6 & 97.7 & 99.3 & 99.3 \\
\hline Temperature $(C)$ & 22 & 22 & 22 & 22 \\
\hline Shake Time & $23.6 \mathrm{hr}$ recontact & $23.6 \mathrm{hr}$ recontact & $23.8 \mathrm{hrs}$ & $23.8 \mathrm{hrs}$ \\
\hline $\mathrm{Kd}(\mathrm{mL} / \mathrm{g})$ & 198.8 & 217.6 & 202.3 & 196.1 \\
\hline Duplicate Average Kd & 208.2 & & 199.2 & \\
\hline Duplicate Average Final [Re] (mg/L) & 0.77 & & 2.395 & \\
\hline
\end{tabular}

\begin{tabular}{|l|l|l|l|}
\hline Measured [Re] in Feed $(\mathrm{mg} / \mathrm{L})$ & 2.37 & 2.42 & 7.18 \\
\hline Sample \# & BNF-SSIX-17-5 & BNF-SSIX-17-5-D & BNF-SSIX-7-D-1 \\
\hline LIMS \# & 300123956 & 300123957 & 300127275 \\
\hline
\end{tabular}

\begin{tabular}{|c|c|c|c|c|}
\hline Sample \# & BNF-SSIX-17-1 & BNF-SSIX-17-1-D & BNF-SSIX-17-2 & BNF-SSIX-17-2-D \\
\hline LIMS \# & 300126842 & 300126843 & 300126845 & 300126846 \\
\hline Solution Mass (g) & 14.7093 & 14.7396 & 14.7016 & 14.7136 \\
\hline Resin Mass (g) & 0.1203 & 0.1213 & 0.1198 & 0.1202 \\
\hline Solution Volume $(\mathrm{mL})$ & 11.96 & 11.98 & 11.95 & 11.96 \\
\hline Initial Conc. (mg/L) & 13.992 & 13.992 & 69.173 & 69.173 \\
\hline Final Conc. $(\mathrm{mg} / \mathrm{L})$ & 3.6199 & 3.1291 & 24.555 & 24.672 \\
\hline solution volume/exchanger mass & 99.4 & 98.8 & 99.8 & 99.5 \\
\hline Temperature (C) & 22 & 22 & 22 & 22 \\
\hline Shake Time & $24.0 \mathrm{hrs}$ & $24.0 \mathrm{hrs}$ & $24.0 \mathrm{hrs}$ & $24.0 \mathrm{hrs}$ \\
\hline $\mathrm{Kd}(\mathrm{mL} / \mathrm{g})$ & 286.0 & 344.3 & 182.0 & 180.2 \\
\hline Duplicate Average Kd & 315.2 & & 181.1 & \\
\hline Duplicate Average Final [Re] (mg/L) & 3.3745 & & 24.6135 & \\
\hline
\end{tabular}

\begin{tabular}{|l|l|}
\hline Measured Re in Feed (mg/L) & 13.992 \\
\hline Sample \# & BNF-SSIX-P-1 \\
\hline LIMS \# & 300126844 \\
\hline
\end{tabular}

\begin{tabular}{|l|}
\hline 69.173 \\
\hline BNF-SSIX-D-2 \\
\hline 300126847 \\
\hline
\end{tabular}


Attachment 1. SuperLig ${ }^{\circledR} 639$ Batch Contact Data (cont.).

Batch \# 980624001DC

\begin{tabular}{|c|c|c|c|c|}
\hline Sample \# & BNF-SSIX-17-3 & BNF-SSIX-17-3-D & BNF-SSIX-17-4 & BNF-SSIX-17-4-D \\
\hline LIMS \# & 300126848 & 300126849 & 300126851 & 300126852 \\
\hline Solution Mass (g) & 14.7095 & 14.7074 & 14.7158 & 14.721 \\
\hline Resin Mass (g) & 0.1205 & 0.1206 & 0.1199 & 0.1205 \\
\hline Solution Volume $(\mathrm{mL})$ & 11.96 & 11.96 & 11.96 & 11.97 \\
\hline Initial [Re] (mg/L) & 152.58 & 152.58 & 222.7 & 222.7 \\
\hline Final $[\mathrm{Re}](\mathrm{mg} / \mathrm{L})$ & 61.996 & 63.513 & 102.03 & 103.21 \\
\hline solution volume/exchanger mass & 99.2 & 99.1 & 99.8 & 99.3 \\
\hline Temperature (C) & 22 & 22 & 22 & 22 \\
\hline Shake Time & $24.0 \mathrm{hr}$ recontact & $24.0 \mathrm{hr}$ recontact & $24.0 \mathrm{hrs}$ & $24.0 \mathrm{hrs}$ \\
\hline$\overline{K d}(\mathrm{~mL} / \mathrm{g})$ & 145.6 & 139.6 & 118.5 & 115.5 \\
\hline Duplicate Average Kd & 142.6 & & 117.0 & \\
\hline Duplicate Average Final [Re] (mg/L) & 62.7545 & & 102.62 & \\
\hline
\end{tabular}

\begin{tabular}{|l|l|}
\hline Measured [Re] in Feed (mg/L) & 152.58 \\
\hline Sample \# & BNF-SSIX-P-2 \\
\hline LIMS \# & 300126850 \\
\hline
\end{tabular}

\begin{tabular}{|l|}
\hline 222.7 \\
\hline BNF-SSIX-P-3 \\
\hline 300126853 \\
\hline
\end{tabular}

Batch $\$ 990420$ DHC720067

\begin{tabular}{|c|c|c|}
\hline Sample \# & BNF-SSIX-17-6 & BNF-SSIX-17-6-D \\
\hline LIMS \# & 300127271 & 300127272 \\
\hline Solution Mass (g) & 22.0561 & 22.0191 \\
\hline Resin Mass (g) & 0.1833 & 0.1832 \\
\hline Solution Volume $(\mathrm{mL})$ & 17.93 & 17.90 \\
\hline Initial $[\mathrm{Re}](\mathrm{mg} / \mathrm{L})$ & 7.18 & 7.18 \\
\hline Final $[\mathrm{Re}](\mathrm{mg} / \mathrm{L})$ & 1.12 & 1.19 \\
\hline solution volume/exchanger mass & 97.8 & 97.7 \\
\hline Temperature (C) & 22 & 22 \\
\hline Shake Time & $23.8 \mathrm{hrs}$ & $23.8 \mathrm{hrs}$ \\
\hline $\mathrm{Kd}(\mathrm{mL} / \mathrm{g})$ & 530.9 & 493.3 \\
\hline Duplicate Average Kd & 512.1 & \\
\hline Duplicate Average Final [Re[ (mg/L) & 1.155 & \\
\hline
\end{tabular}

\begin{tabular}{|l|l|}
\hline Measured [Re] in Feed (mg/L) & 7.18 \\
\hline Sample \# & BNF-SSIX-D-1 \\
\hline LIMS \# & 300127275 \\
\hline
\end{tabular}


Attachment 1. SuperLig ${ }^{\circledR} 639$ Batch Contact Data (continued).

Batch \#981015DHC720011

\begin{tabular}{|c|c|c|c|c|}
\hline Sample \# & BNF-SSIX-10-1 & BNF-SSIX-10-1-D & BNF-SSIX-10-3 & BNF-SSIX-10-3-D \\
\hline LIMS \# & 300123956 & 300123957 & 300124008 & 300124012 \\
\hline Solution Mass (g) & 21.9902 & 21.8143 & 17.9917 & 17.5916 \\
\hline Resin Mass (g) & 0.1809 & 0.1801 & 0.1499 & 0.1503 \\
\hline Solution Volume $(\mathrm{mL})$ & 17.88 & 17.74 & 14.63 & 14.30 \\
\hline Initial $[\mathrm{Re}](\mathrm{mg} / \mathrm{L})$ & 6.9605 & 6.9605 & 1.3958 & 1.4198 \\
\hline Final $[\operatorname{Re}](\mathrm{mg} / \mathrm{L})$ & 1.3958 & 1.4198 & 0.2632 & 0.26313 \\
\hline solution volume/exchanger mass & 98.8 & 98.5 & 97.6 & 95.2 \\
\hline Temperature (C) & 20 & 20 & 19 & 19 \\
\hline Shake Time & $24.1 \mathrm{hr}$ & $24.1 \mathrm{hr}$ & $24.0 \mathrm{hr}$ recontact & $24.0 \mathrm{hr}$ recontact \\
\hline $\mathrm{Kd}(\mathrm{mL} / \mathrm{g})$ & 395.2 & 385.4 & 421.2 & 419.6 \\
\hline Duplicate Average Kd & 390.3 & & 420.4 & \\
\hline \begin{tabular}{|l} 
Duplicate Average Final [Re] (mg/L) \\
\end{tabular} & 1.41 & & 0.263 & \\
\hline
\end{tabular}

\begin{tabular}{|l|l|l|l|}
\hline Measured [Re] in Feed (mg/L) & 6.96 & & \\
\hline Sample \# & $\begin{array}{l}\text { BNF-SSIX-10-1- } \\
\text { FD }\end{array}$ & & \\
\hline LIMS \# & 300123958 & & \\
\hline
\end{tabular}

\begin{tabular}{|c|c|c|c|c|}
\hline Sample \# & BNF-SSIX-10-5 & BNF-SSIX-I0-5-D & BNF-SSIX-10-2 & BNF-SSIX-10-2-D \\
\hline LIMS \# & 300124167 & 300124168 & 300123959 & 300123960 \\
\hline Solution Mass (g) & 13.9225 & 13.0358 & 21.8462 & 21.8045 \\
\hline Resin Mass (g) & 0.1113 & 0.1184 & 0.1827 & 0.1816 \\
\hline Solution Volume $(\mathrm{mL})$ & 11.32 & 10.60 & 17.76 & 17.73 \\
\hline Initial Conc. (mg/L) & 0.2632 & 0.26313 & 72.781 & 72.781 \\
\hline Final Conc. (mg/L) & 0.056 & 0.057 & 16.119 & 16.561 \\
\hline solution volume/exchanger mass & 101.7 & 89.5 & 97.2 & 97.6 \\
\hline Temperature (C) & 20 & 20 & 20 & 20 \\
\hline Shake Time & $24.0 \mathrm{hr}$ recontact & $24.0 \mathrm{hr}$ recontact & $24.1 \mathrm{hrs}$ & $24.1 \mathrm{hrs}$ \\
\hline $\mathrm{Kd}(\mathrm{mL} / \mathrm{g})$ & 377.4 & 324.7 & 342.8 & 332.4 \\
\hline Duplicate Average Kd & 351.0 & & 337.6 & \\
\hline $\begin{array}{l}\text { Duplicate Average Final [Re] } \\
\text { (mg/L) }\end{array}$ & 0.0565 & & 16.34 & \\
\hline Measured [Re] in Feed (mg/L) & 6.96 & & 72.78 & \\
\hline Sample \# & BNF-SSIX-10-1-FD & & $\begin{array}{l}\text { BNF-SSIX-10-2- } \\
\text { FD }\end{array}$ & \\
\hline LIMS \# & 300123958 & & 300123961 & \\
\hline
\end{tabular}




\subsection{Attachment 2. SuperLig ${ }^{\circledR} 639$ Column Data.}

\begin{tabular}{|c|c|}
\hline \multicolumn{2}{|c|}{ SuperLig 639 Bat } \\
\hline \multicolumn{2}{|l|}{ Exp. 1} \\
\hline \multicolumn{2}{|c|}{$0.51 \mathrm{~cm} / \mathrm{min}, 2.69$} \\
\hline \multicolumn{2}{|c|}{ ICP-MS Analysis } \\
\hline \multicolumn{2}{|c|}{ Feed Cycle } \\
\hline Feed & 16 \\
\hline$\# \mathrm{BV}$ & $\mathrm{C} / \mathrm{Co}$ \\
\hline 4.2 & 0.001 \\
\hline 8.5 & 0.002 \\
\hline 29.6 & 0.050 \\
\hline 48.8 & 0.160 \\
\hline 68.0 & 0.331 \\
\hline 87.2 & 0.489 \\
\hline 107.9 & 0.675 \\
\hline 128.6 & 0.806 \\
\hline 149.3 & 0.838 \\
\hline 170.0 & 0.894 \\
\hline 190.7 & 0.906 \\
\hline 211.4 & 0.913 \\
\hline 226.4 & 0.913 \\
\hline 236.3 & 0.944 \\
\hline 246.1 & 0.956 \\
\hline 256.0 & 0.950 \\
\hline 265.8 & 0.925 \\
\hline 275.6 & 0.931 \\
\hline 285.5 & 0.925 \\
\hline 295.3 & 0.913 \\
\hline 305.2 & 0.919 \\
\hline
\end{tabular}

Exp. 2

$5.2 \mathrm{~cm} / \mathrm{min}, 2.69 \mathrm{~cm} \mathrm{ID} \mathrm{Column}$

ICP-ES Analysis

Feed Cycle Water Elution

Feed $\quad 15.9 \mathrm{mg} / \mathrm{L} \mathrm{Re}$

\# BV C/Co \# BV [Re] (mg/L)

\begin{tabular}{|c|c|}
\hline 2.3 & 0.103 \\
\hline 12.2 & 0.328 \\
\hline 31.5 & 0.540 \\
\hline 41.7 & 0.697 \\
\hline 62.2 & 0.774 \\
\hline 82.7 & 0.801 \\
\hline 103.2 & 0.847 \\
\hline 123.7 & 0.850 \\
\hline 144.2 & 0.869 \\
\hline 164.7 & 0.924 \\
\hline
\end{tabular}

\begin{tabular}{|c|c|}
\hline 1.2 & 21.800 \\
\hline 2.3 & 195.000 \\
\hline 3.6 & 230.000 \\
\hline 4.8 & 114.000 \\
\hline 5.9 & 40.400 \\
\hline 7.1 & 12.400 \\
\hline 8.2 & 3.500 \\
\hline 9.3 & 1.600 \\
\hline 9.4 & 0.630 \\
\hline 10.5 & 0.463 \\
\hline 11.6 & 0.323 \\
\hline 12.8 & 0.255 \\
\hline 13.9 & 0.208 \\
\hline 16.1 & 0.145 \\
\hline 18.4 & 0.110 \\
\hline 20.6 & 0.093 \\
\hline 22.8 & 0.075 \\
\hline 25.1 & 0.059 \\
\hline
\end{tabular}

\# BV
\begin{tabular}{|c|c|}
\hline 1.7 & $\mathrm{Re}](\mathrm{mg} / \mathrm{L})$ \\
\hline 2.9 & 27.7 \\
\hline 5.1 & 309.1 \\
\hline 7.4 & 27.7 \\
\hline 9.7 & 22.2 \\
\hline 27.7 & 0.1 \\
\hline 29.7 & 0.1 \\
\hline
\end{tabular}


Attachment 2. SuperLig ${ }^{\circledR} 639$ Column Data (cont.)

Exp. 3

$11.0 \mathrm{~cm} / \mathrm{min}, 2.69 \mathrm{~cm}$ ID Column ICP-ES Analysis

Load Cycle

Feed

Water/Acid Elution

$16 \mathrm{mg} / \mathrm{L} \mathrm{Re}$

\begin{tabular}{|c|c|}
\multicolumn{1}{c}{ \# BV } & C/Co \\
\hline 2.6 & 0.126 \\
\hline 5.1 & 0.348 \\
\hline 9.1 & 0.506 \\
\hline 10.1 & 0.539 \\
\hline 12.7 & 0.618 \\
\hline 19.0 & 0.628 \\
\hline 21.7 & 0.589 \\
\hline 24.3 & 0.650 \\
\hline 27.4 & 0.598 \\
\hline 35.5 & 0.650 \\
\hline 45.5 & 0.725 \\
\hline 55.6 & 0.800 \\
\hline 65.6 & 0.781 \\
\hline 75.7 & 0.756 \\
\hline 85.7 & 0.775 \\
\hline 95.8 & 0.800 \\
\hline 105.8 & 0.825 \\
\hline 125.9 & 0.794 \\
\hline 146.3 & 0.813 \\
\hline 166.8 & 0.850 \\
\hline 187.2 & 0.844 \\
\hline 207.6 & 0.875 \\
\hline 289.3 & 0.925 \\
\hline 330.1 & 0.881 \\
\hline & \\
\hline
\end{tabular}

Exp. 4

$0.48 \mathrm{~cm} / \mathrm{min}, 4 \mathrm{~cm}$ ID Column ICP-ES Analysis Load Cycle

Feed

Water Elution

\# BV [Re] (mg/L)

\# BV $\quad \mathrm{C} / \mathrm{Co}$

\# BV $\quad[\operatorname{Re}](\mathrm{mg} / \mathrm{L})$

\begin{tabular}{|c|c|}
\hline 0.3 & 0.048 \\
\hline 0.4 & 0.004 \\
\hline 11.3 & 0.065 \\
\hline 22.0 & 0.273 \\
\hline 32.5 & 0.312 \\
\hline 43.0 & 0.403 \\
\hline 53.6 & 0.487 \\
\hline 85.2 & 0.649 \\
\hline 106.3 & 0.706 \\
\hline 124.4 & 0.723 \\
\hline 179.1 & 0.824 \\
\hline
\end{tabular}

\begin{tabular}{|c|c|}
\hline 1.0 & 34.0 \\
\hline 2.0 & 39.0 \\
\hline 3.0 & 116.0 \\
\hline 4.0 & 327.0 \\
\hline 5.0 & 242.0 \\
\hline 6.0 & 54.0 \\
\hline 8.0 & 9.7 \\
\hline 10.0 & 2.9 \\
\hline 12.0 & 2.8 \\
\hline 15.0 & 1.2 \\
\hline 18.0 & 0.5 \\
\hline 27.0 & 0.3 \\
\hline 29.0 & 0.1 \\
\hline
\end{tabular}


Attachment 2. SuperLig ${ }^{\circledR} 639$ Column Data (cont.)

SuperLig ${ }^{639}$ Mixture of Batches 981015 DHC720011 and 990420 DHC720067

Exp. 5

$0.43 \mathrm{~cm} / \mathrm{min}, 2.69 \mathrm{~cm}$ ID Column

ICP-ES Analysis

Load Cycle

Water Elution

Feed

$14 \mathrm{mg} / \mathrm{L} \operatorname{Re}$

\begin{tabular}{|c|c|}
\hline \# BV & C/Co \\
\hline 5.0 & 0.008 \\
\hline 11.0 & 0.010 \\
\hline 29.0 & 0.034 \\
\hline 64.6 & 0.154 \\
\hline 101.8 & 0.308 \\
\hline 135.6 & 0.454 \\
\hline 169.5 & 0.569 \\
\hline 203.3 & 0.700 \\
\hline 236.1 & 0.769 \\
\hline 252.2 & 0.846 \\
\hline 268.3 & 0.846 \\
\hline 284.4 & 0.846 \\
\hline 292.4 & 0.846 \\
\hline
\end{tabular}

\begin{tabular}{|c|c|}
\hline \# BV & {$[\mathrm{Re}](\mathrm{mg} / \mathrm{L})$} \\
\hline$\overline{1}$ & 13 \\
\hline 2 & 18 \\
\hline 3 & 89 \\
\hline 4 & 391 \\
\hline 5 & 403 \\
\hline 6 & 303 \\
\hline 7 & 199 \\
\hline 8 & 134 \\
\hline 10 & 55 \\
\hline 11 & 41 \\
\hline 12 & 28 \\
\hline 15 & 11 \\
\hline 25 & 4 \\
\hline 27 & 2.8 \\
\hline
\end{tabular}


8.3 Attachment 3. Flow Rate Analysis for SuperLig ${ }^{\circledR} 639$ Column Feed, Wash and Elution Cycles.

Bed Diameter Feed Feed Range Post-feed water wash Elution*

\begin{tabular}{|c|c|c|c|c|}
\multicolumn{1}{c}{$\mathrm{cm}$} & $\mathrm{cm} / \mathrm{min}(\mathrm{BV} / \mathrm{hr})$ & $\mathrm{cm} / \mathrm{min}$ & $\mathrm{cm} / \mathrm{min}(\mathrm{BV} / \mathrm{hr})$ & $\mathrm{cm} / \mathrm{min}(\mathrm{BV} / \mathrm{hr})$ \\
\hline 2.7 & $0.51(3.4)$ & $0.42-0.53$ & $0.54(3.6)$ & $0.16 .(1.1) \mathrm{A}$ \\
\hline 2.7 & $5.2(34.7)$ & $5.2-5.7$ & $0.54(3.6)$ & $0.16(1.1) \mathrm{W}$ \\
\hline 2.7 & $11.0(73.4)$ & $10.9-11.2$ & $0.48(3.2)$ & $0.15(1.0) \mathrm{A}$ \\
\hline 4.0 & $0.48(6.9)$ & $0.42-0.56$ & $0.19(2.7)$ & $0.19(2.7) \mathrm{W}$ \\
\hline 2.7 & $0.43(2.9)$ & $0.41-0.48$ & $0.41(2.8)$ & $0.41(2.8) \mathrm{W}$ \\
\hline
\end{tabular}

* The letters $\mathrm{A}$ and $\mathrm{W}$ indicate whether acid or water were used for elution, respectively. 